OPEN ACCESS

Edited by:

Kim T. Mueser,

Boston University, USA

Reviewed by:

Lauren Gibson,

Temple University, USA

Craig Steel,

University of Reading, UK

*Correspondence:

Danessa Mayo

dmayo@ucdavis.edu

Specialty section:

This article was submitted to

Psychopathology,

a section of the journal

Frontiers in Psychiatry

Received: 15 December 2016

Accepted: 27 March 2017

Published: 20 April 2017

Citation:

Mayo $D$, Corey S, Kelly $L H$,

Yohannes $S$, Youngquist $A L$,

Stuart BK, Niendam TA and Loewy RL (2017) The Role of Trauma

and Stressful Life Events among

Individuals at Clinical High Risk for

Psychosis: A Review.

Front. Psychiatry 8:55.

doi: 10.3389/fpsyt.2017.00055

\section{The Role of Trauma and Stressful Life Events among Individuals at Clinical High Risk for Psychosis: A Review}

\author{
Danessa Mayo ${ }^{1 *}$, Sarah Corey², Leah H. Kelly², Seghel Yohannes², Alyssa L. Youngquist ${ }^{2}$, \\ Barbara K. Stuart ${ }^{2}$, Tara A. Niendam ${ }^{1}$ and Rachel L. Loewy ${ }^{2}$ \\ ${ }^{1}$ Imaging Research Center, Department of Psychiatry and Behavioral Sciences, University of California Davis, Sacramento, \\ CA, USA, ${ }^{2}$ Department of Psychiatry, University of California San Francisco, San Francisco, CA, USA
}

The experience of childhood trauma (CT) and stressful life events (SLEs) is associated with subsequent development of a variety of mental health conditions, including psychotic illness. Recent research identifying adolescents and young adults at clinical high risk (CHR) for psychosis allows for prospective evaluation of the impact of trauma and adverse life events on psychosis onset and other outcomes, addressing etiological questions that cannot be answered in studies of fully psychotic or non-clinical populations. This article provides a comprehensive review of the current emerging literature on trauma and adverse life events in the $\mathrm{CHR}$ population. Up to $80 \%$ of $\mathrm{CHR}$ youth endorse a lifetime history of childhood traumatic events and victimization (e.g., bullying). Several studies have shown that the experience of CT predicts psychosis onset among CHR individuals, while the literature on the influence of recent SLEs (e.g., death of a loved one) remains inconclusive. Multiple models have been proposed to explain the link between trauma and psychosis, including the stress-vulnerability and stress-sensitivity hypotheses, with emphases on both cognitive processes and neurobiological mechanisms (e.g., the hypothalamic-pituitary-adrenal axis). Despite the preponderance of $\mathrm{CHR}$ individuals who endorse either CT or SLEs, no clinical trials have been conducted evaluating interventions for trauma in $\mathrm{CHR}$ youth to date. Furthermore, the current process of formal identification and assessment of trauma, SLEs, and their impact on CHR youth is inconsistent in research and clinical practice. Recommendations for improving trauma assessment, treatment, and future research directions in the CHR field are provided.

Keywords: clinical high risk, trauma, early psychosis, stressful life events, ultra-high risk, schizophrenia

\section{INTRODUCTION}

While a wealth of data has demonstrated indirect associations between childhood trauma (CT) and psychosis in adulthood, the role of CT in the etiology of psychosis and its potential underlying mechanisms are not yet well-understood (1-4). CT is the experience of a highly distressing event or situation during youth that is beyond one's capacity for coping and/or control $(5,6)$. Prospective studies of individuals who later develop psychosis provide a unique opportunity to examine potential risk factors, resilience factors, and mechanisms that may link CT and psychosis. Over the past 
decade, the "clinical high risk" (CHR) paradigm has been used to identify adolescents and young adults at increased imminent risk for developing psychotic disorders. Thus, CHR research makes an important contribution to understanding the potential etiologic role of CT in the development of psychosis. In this paper, we review the emerging literature on trauma and stressful life events (SLEs) in CHR individuals, with a focus on both behavioral and neurobiological studies. This paper also provides a risk model that explains the trauma and psychosis relationship. Further, current and important future directions for assessment, research, and clinical care are highlighted.

\section{The CHR Syndrome}

The CHR syndrome, also termed "ultra high risk" by some research groups, is typically diagnosed using one of two semistructured interviews-the Structured Interview for Psychosis Risk Syndromes (SIPS) or the Comprehensive Assessment of At-Risk Mental States (CAARMS) $(7,8)$. The interviews assess a variety of subthreshold psychotic-like experiences (i.e., positive, negative, and disorganized symptoms), general psychopathology (e.g., depression, anxiety), functioning, and family history. Despite slight differences in diagnostic criteria and terminology, both instruments diagnose three possible risk syndromes and have shown high agreement ratings (86\%) (9). Other instruments are also used to diagnose individuals at elevated risk for psychosis based on subjective cognitive changes (10, 11). As such, these selected standardized measures have been utilized in international early psychosis (EP) clinics and research programs in an effort to reach diagnostic consensus and validity across sites.

\section{Psychosis Risk and Outcomes}

Outcomes for CHR individuals are heterogeneous: proportion estimates of individuals who transition to full psychosis range from $10-70 \%$ due to ascertainment strategy, diagnostic instrument, and follow-up period used (12). The largest individual study using the SIPS demonstrated a conversion rate of $35 \%$ to full psychosis by 2.5 years $(12,13)$. The CHR syndrome confers higher and more immediate risk than heritability estimates of $10 \%$ risk among first-degree family members (i.e., parent-offspring; full siblings), although not as high as the $50 \%$ rate of psychosis among identical twins $(14,15)$. Several factors appear to increase the risk for developing psychotic disorders among those with CHR syndromes: poor premorbid functioning, severe positive symptoms (i.e., elevated unusual thought content, increased suspiciousness), increased anhedonia, poor cognition (i.e., impaired verbal learning, decision-making, memory), decline in social and role functioning, substance abuse history, and family history of psychosis (16-19).

It is important to note that approximately $65 \%$ of $\mathrm{CHR}$ individuals do not develop psychosis within the first 3 years after diagnosis of the syndrome. A significant proportion (46\%) of non-converters experience remission of their attenuated psychosis (20). Yet, many of those who do not develop psychosis continue to experience psychiatric problems such as mood, anxiety, and substance use disorders $(21,22)$. By targeting individuals presenting with attenuated psychotic symptoms or other markers indicative of increased psychosis risk, CHR programs seek to identify factors that could be addressed in order to mitigate a variety of negative outcomes and support resilience. To date, a number of potential factors related to outcomes in CHR populations have been identified, including the role of trauma and stress.

\section{TRAUMA EXPERIENCES IN THE CHR POPULATION}

The experience of CT leads to a cascade of negative effects on typical child and adult development $(6,23)$. A strong body of literature on the general population of adolescents and young adults (via school-wide samples, research and clinical settings, and longitudinal population studies) suggests that CT contributes to poor cognitive, social, medical, and developmental functioning; moreover, CT is a significant risk factor for later development of serious mental illness (SMI), including schizophrenia (24-34). The lifetime prevalence rate of trauma exposure is high among both men (60.7\%) and women (51.2\%) (35). Individuals ages 14-24 reported exposure to one or more traumatic experiences, such as physical abuse (50\%), child abuse, or neglect (13\%) (36); approximately $68 \%$ of youth by age 16 endorsed at least one trauma experience (37). CT is linked with a variety of adult psychopathology outcomes. Compared to adult participants with no history of CT, those with exposure to four or more traumas were at substantial risk (4- to 12-fold) for developing substance use, depression, and suicidality (38). Thus, several studies on stress and trauma posit that the experience of CT and prolonged early stressors may contribute to the increased risk of future SMI (24-34, 39-41).

To date, only 24 studies, representing 14 distinct samples, report on CT in CHR populations; of these, 11 followed the participants longitudinally to examine $\mathrm{CT}$ as a risk factor for developing psychosis $(2,34,40,42-62)$. Sixteen of these studies were included in a recent review and meta-analysis (5), which summarized the existing studies in a series of tables. We refer the reader to this paper by Kraan and colleagues (5) and have summarized more recent publications $(8,34,45,49,51,52,55$, 59) in a parallel table below (see Table 1).

The meta-analysis concluded that CT is a largely prevalent experience among the CHR population (86.8\%) compared to healthy controls (HC) (5). Such alarmingly high rates of CT endorsed by the CHR population is comparable to the prevalence rate among individuals with schizophrenia (85\%) (5). We expand upon the meta-analysis by reviewing different types of trauma in the CHR syndrome based on all current available information below.

\section{Associated Findings on Trauma in the CHR Population}

Clinical high risk individuals may be at risk for experiencing various forms of traumatic experiences that are common within the general population. The meta-analysis by Kraan and colleagues (5) reported a mean prevalence rate of $86.8 \% \mathrm{CT}$ in CHR studies $(2,40,42,51,56)$. The range of rates $(35.9-70 \%)$ may be partially explained by the type of trauma being examined and the gender sample distribution (e.g., sexual abuse) $(40,53)$ and type of 
TABLE 1 | Studies on clinical high risk (CHR) individuals with trauma history and/or stressful life events.

\begin{tabular}{|c|c|c|c|c|c|c|c|c|c|}
\hline Reference & Study & Outcome measure & Trauma instrument & $\begin{array}{c}\text { CHR } \\
\text { instrument }\end{array}$ & Study design & Participants & $\begin{array}{l}\text { Gender } \\
\text { (male) }\end{array}$ & $\begin{array}{c}\text { Mean age } \\
\text { (range) }\end{array}$ & Conclusion \\
\hline $\begin{array}{l}\text { Russo et al. } \\
\text { (49) }\end{array}$ & $\begin{array}{l}\text { CAMEO United } \\
\text { Kingdom; } \\
\text { NIHR, United } \\
\text { Kingdom }\end{array}$ & $\begin{array}{l}\text { Examine trauma } \\
\text { characteristics associated } \\
\text { with } \mathrm{CHR}\end{array}$ & THS & CAARMS & $\begin{array}{l}\text { 2-year follow } \\
\text { along }\end{array}$ & $\begin{array}{l}N=60 \mathrm{CHR} \\
N=60 \mathrm{HC}\end{array}$ & $51.7 ; 43.3 \%$ & $\begin{array}{c}19.89 \\
(16.41-30.21) \\
22.6 \\
(16.18-35.57)\end{array}$ & $\begin{array}{l}\text { Age at study entry, number of traumas, and } \\
\text { age at trauma exposure were predictors of } \\
\text { CHR group association }\end{array}$ \\
\hline $\begin{array}{l}\text { Thompson } \\
\text { et al. (55) }\end{array}$ & PACE, Australia & $\begin{array}{l}\text { Examine relationship } \\
\text { between trauma } \\
\text { (specifically sexual } \\
\text { trauma) and conversion to } \\
\text { psychosis }\end{array}$ & CTQ & CAARMS & $\begin{array}{l}\text { Follow along, } \\
\text { length not } \\
\text { specified }\end{array}$ & $\begin{array}{l}N=416 \mathrm{CHR} \\
\text { [similar sample } \\
\text { as Thompson } \\
\text { et al. (52)] }\end{array}$ & Unspecified & $\begin{array}{l}\text { Unspecified } \\
\text { age and } \\
\text { range }\end{array}$ & $\begin{array}{l}\text { Positive correlation between childhood } \\
\text { sexual abuse and conversion to psychosis. } \\
\text { Relationship unique to sexual trauma. }\end{array}$ \\
\hline $\begin{array}{l}\text { Kraan et al. } \\
\text { (34) }\end{array}$ & $\begin{array}{l}\text { Dutch } \\
\text { Prediction of } \\
\text { Psychosis } \\
\text { Study, } \\
\text { Netherlands }\end{array}$ & $\begin{array}{l}\text { Determine the relationship } \\
\text { between childhood trauma } \\
\text { (CT) and functional/clinical } \\
\text { outcome overtime }\end{array}$ & TADS & SIPS & $\begin{array}{l}\text { 24-month follow } \\
\text { along; follow-up } \\
\text { at 9-month, } \\
\text { 18-month, and } \\
\text { 24-month }\end{array}$ & $N=125 \mathrm{CHR}$ & $68.00 \%$ & $\begin{array}{c}17.7 \\
\text { (unspecified) }\end{array}$ & $\begin{array}{l}\text { Trauma not related to conversion, differential } \\
\text { symptom, or functioning overtime. Positive } \\
\text { correlations between level of trauma and } \\
\text { attenuated positive symptoms, general } \\
\text { symptoms, and depression. Trauma negatively } \\
\text { correlated with functioning at baseline and } \\
\text { follow-up }\end{array}$ \\
\hline $\begin{array}{l}\text { Üçok et al. } \\
\text { (59) }\end{array}$ & $\begin{array}{l}\text { Psychotic } \\
\text { Disorders } \\
\text { Research } \\
\text { Program, } \\
\text { Istanbul }\end{array}$ & $\begin{array}{l}\text { Investigate association } \\
\text { between } \mathrm{CT} \text { and } \mathrm{CHR} \\
\text { cognitive functioning }\end{array}$ & CTQ & BPRS & Cross-sectional & $N=53 \mathrm{CHR}$ & $73.60 \%$ & $\begin{array}{c}21.1 \\
\text { (unspecified) }\end{array}$ & $\begin{array}{l}\text { CHR participants with trauma history had } \\
\text { worse attention and working memory. } \\
\text { Cognitive flexibility and interference inhibition } \\
\text { scores lower than those without a history of } \\
\text { CT. No association between trauma and verbal } \\
\text { learning/memory. Suggests CT and cognitive } \\
\text { deficits may be associated with types of } \\
\text { trauma }\end{array}$ \\
\hline $\begin{array}{l}\text { Yung et al. } \\
\text { (61) }\end{array}$ & PACE, Australia & $\begin{array}{l}\text { Examine clinical predictors } \\
\text { for poor functional } \\
\text { outcomes in CHR patients. } \\
\text { Examine a relationship } \\
\text { between poor functioning } \\
\text { and conversion to } \\
\text { psychosis }\end{array}$ & CTQ & CAARMS & $\begin{array}{l}\text { 14-year follow } \\
\text { along }\end{array}$ & $N=268 \mathrm{CHR}$ & $43.20 \%$ & $\begin{array}{l}\text { Unspecified } \\
\text { (15-30) }\end{array}$ & $\begin{array}{l}\text { Childhood maltreatment and psychosis } \\
\text { significantly predicted poor functional outcome } \\
\text { No association between positive symptoms } \\
\text { and follow-up functioning. Cross-sectional } \\
\text { relationship found between long-term poor } \\
\text { functioning and negative symptoms at follow- } \\
\text { up in both converters and non-converters }\end{array}$ \\
\hline $\begin{array}{l}\text { Kline et al. } \\
(45)\end{array}$ & $\begin{array}{l}\text { Strive for } \\
\text { Wellness, } \\
\text { Maryland }\end{array}$ & $\begin{array}{l}\text { Examine relationship } \\
\text { between trauma and early } \\
\text { psychosis and psychosis } \\
\text { risk symptoms in youth }\end{array}$ & KSADS-PL & SIPS & Cross-sectional & $\begin{array}{c}N=60 \mathrm{CHR} / \\
\mathrm{EP} ; N=65 \mathrm{LR}\end{array}$ & $49.00 \%$ & $\begin{array}{c}15.88 \\
\text { (unspecified) }\end{array}$ & $\begin{array}{l}\text { Trauma history related to positive symptoms } \\
\text { in both groups. LR group reported heightened } \\
\text { suspiciousness with a history of exposure to } \\
\text { violence. CHR/EP group reported heightened } \\
\text { levels of suspiciousness regardless of type of } \\
\text { violence exposure }\end{array}$ \\
\hline
\end{tabular}




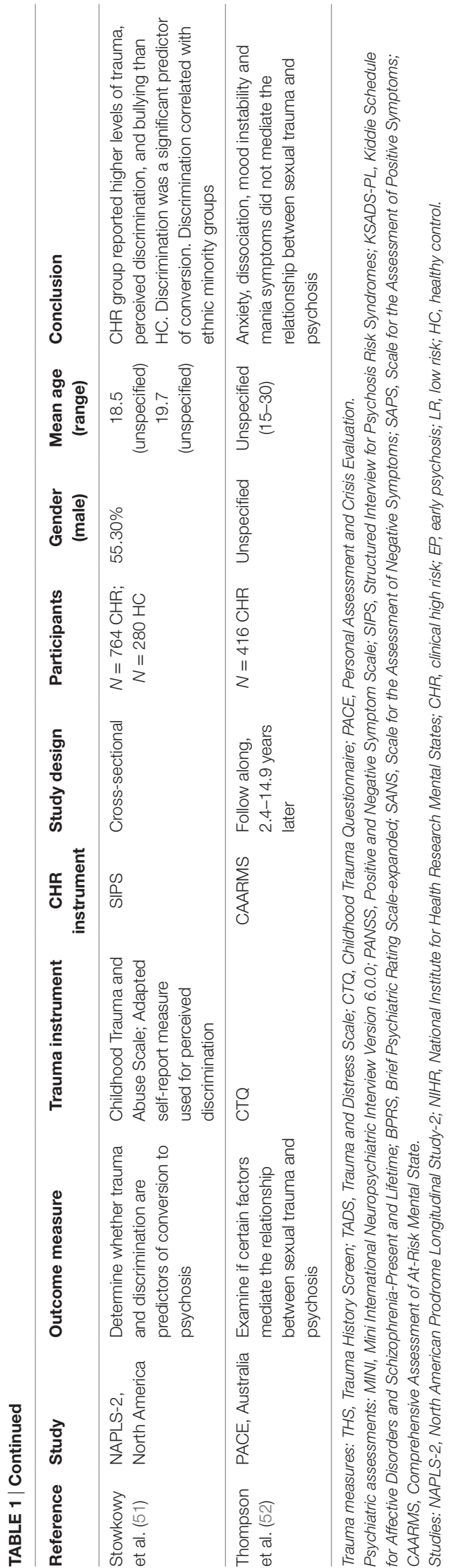

assessment used (e.g., medical records review, semi-structured interview, self-report), with self-report measures associated with higher rates of trauma disclosure [e.g., Childhood Trauma Questionnaire (CTQ), Early Trauma Inventory] (40-91\%) (40, $42,44,55,59)$. Some measures assess narrowly defined trauma, while others are more broad, including major life events. Eight of the studies were based on small samples of less than 100 participants, with some as small as 25 subjects $(40,44,46,50,53$, $56,58,62)$. Smaller samples are more easily biased by sampling differences and thus contribute to heterogeneity of results and lack of reproducibility (63). The largest sample reported $46.2 \%$ of CHR individuals with CT $(n=764)$, a majority of those who endorsed severe to extreme rates of trauma on the brief CTQ (51, $52,55)$. As a whole, these studies highlight the preponderance of $\mathrm{CT}$ experiences among the CHR population and the importance of such information for clinical consideration.

Four studies formally compared CT rates in CHR samples with HC populations matched on demographic variables (i.e., age, gender, socioeconomic status) and found higher rates of abuse among CHR groups $(2,50,58)$. Research suggests that CHR individuals may be at greater risk for physical trauma than the general population (17\%) (64). In a small study of $30 \mathrm{CHR}$ participants, $83 \%$ reported a physical abuse history (56). A study on a CHR sample reported more violent $(71.7 \%)$ and non-violent events (53.3\%) than the low-risk group (48.4\% violent; $33.9 \%$ non-violent events) (45). Physical trauma is also associated with poorer cognitive functioning, which is a significant concern for CHR individuals, as poor premorbid cognitive functioning may add to their psychopathology risk $(59,61)$.

Individuals with a sexual abuse history are at higher risk for developing mood and anxiety disorders, substance abuse, posttraumatic stress disorder (PTSD), eating disorders, suicidal behaviors, and psychosis (65-69). Across studies, approximately $22-31.1 \%$ of CHR individuals endorsed a sexual trauma history $(34,40,44,49,52,53,56)$ compared to the lifetime prevalence rate in the general population (15-25\%) (70). Similarly, a study of $92 \mathrm{CHR}$ individuals with a sexual abuse history endorsed higher rates of positive symptoms of a sexual nature (e.g., feelings of being watched while bathing, hearing voices say sexual statements) than HC (53). This may indicate that previous experiences of sexual trauma contribute in part to the nature of CHR individuals' emerging positive psychotic symptoms. CHR youth showed even higher rates of emotional abuse (41.5-75\%) and emotional neglect $(59-100 \%)(56,58,59)$ compared to HC $(33 \%)$ (58). Furthermore, emotional abuse and neglect among CHR individuals have also been associated with greater Schneiderian first-rank symptoms, more elevated Schneiderian total score, and depression severity level (2).

Bullying victimization is becoming increasingly recognized as an important form of adverse childhood experience (24). Bullying has been associated with a variety of poor outcomes, ranging from poor self-esteem, depression, suicidality, aggression, and psychosis being the most serious (71). CHR youth endorsed a lifetime history of physical and psychological bullying (30 and 60\%, respectively) that was much higher than HC (14 and 36\%, respectively) (42). Bullying history among CHR youth was significantly associated with poorer social functioning (42) 
and was more likely to persist into adult psychiatric disorders (71). As such, it is imperative that more research is conducted to examine the relationship between childhood bullying and psychosis symptoms.

Trauma is often experienced as a result of developing psychosis, due to the experience of frightening psychotic symptoms or hospitalizations, especially involuntary treatment. Prevalence of psychosis-associated trauma symptoms among individuals with full psychotic disorders varies from 11-67\% (72, 73). They may be associated with factors such as trauma history prior to inpatient hospitalization (e.g., physical or sexual abuse) and other psychological factors (e.g., negative event appraisals, poor coping skills) $(74,75)$. However, some studies did not find any associations with psychosis-related trauma symptoms and the number of negative experiences from inpatient psychiatric hospitalizations $(73,76)$. It may be important to ascertain whether other patientlevel factors, such as the level of distress attributed to the inpatient hospitalization, legal status, and involuntary hospitalization may be associated with psychosis-related trauma symptoms $(73,75$, 76). To date, there are no specific studies that focus on trauma symptoms associated with psychiatric hospitalization among CHR individuals. This is an important research area in need of further exploration and highlights the usefulness of examining the impact of CT in the CHR population, prior to the potentially traumatizing effects of involuntary hospitalization that can accompany the onset of a full psychotic disorder.

Only a few published studies have explored the demographic characteristics of trauma in CHR individuals. A study on gender differences showed that stress-sensitivity scores among CHR females (but not males) mediated the association between trauma and attenuated positive psychotic symptoms, which suggests that females cope with trauma differently and tend to internalize their experiences (77). While ethnic sample variability (i.e., majority Caucasian women) was a possible research limitation, this is consistent with the common finding that females with psychosis are more likely to endorse a trauma history (e.g., sexual abuse) than males $(42,53)$ and are more likely to have an affective disorder associated with their diagnosis (78). Similarly, limited studies regarding ethnicity (e.g., perceived discrimination, social adversity) and its relationship with trauma in CHR groups currently exist (51). The current collective studies on CHR groups with trauma experiences suggest the importance of continued research into its associated influence on psychosis risk.

\section{Trauma and CHR Conversion to Psychosis}

Trauma has been repeatedly found to predict transition to psychosis in CHR samples. Sexual abuse is the most common form of CT associated with later psychosis conversion, followed by physical abuse $(3,40,53,55,60)$. Moreover, emotional abuse and physical neglect have been identified as potential risk factors for psychosis conversion (58). Similar to findings on sexual abuse history, the increased severity and duration of individuals' bullying history has been linked to the emergence of psychosis symptoms (71). While elevated rates of trauma history were found among CHR individuals in the NAPLS sample and trauma history was a significant predictor of psychosis conversion in the univariate and multivariate analyses, it was not a statistically significant predictor after controlling for prodromal symptom severity, social functioning decline, verbal learning, and memory (16). Thus, the power of trauma to predict conversion must be examined in the context of other predictors in order to determine its relative impact and possible relationship to other predictive factors.

\section{SLEs IN THE CHR POPULATION}

It is not yet clear whether the impact of trauma on individuals with CHR is specific to narrowly defined traumatic events or also includes the cumulative effects of adverse or SLEs that have also been linked with adult psychopathology, including psychosis risk $(79,80)$. In fact, many studies that purport to measure traumatic events include less severe SLEs, which consist of dangerous or life-changing experiences that have occurred for an individual (5) and may cause disruption in the typical developmental trajectory of youth through adulthood. Exposure to SLEs are associated with increased risk for depressed mood, anxiety, eating disorders, suicidality, substance use, and psychosis symptoms in later adolescence $(29,81-85)$. Current findings on the SLE-psychosis risk relationship are inconclusive; some cited a positive relationship $(39,51,86,87)$ while others did not $(43,47,48,57)$. Kraan and colleagues (5) indicated that recent SLEs were less commonly endorsed by $\mathrm{CHR}$ youth than $\mathrm{HC}$, which may be due to increasing negative symptoms of psychosis (e.g., increased avolition, social withdrawal) that limit activities. Increased research efforts are underway to improve current understanding of the relationship between SLEs and psychosis.

\section{COMORBID DISORDERS AND DIFFERENTIAL DIAGNOSIS IN THE CHR POPULATION}

The specificity of the relationship between trauma and CHR symptoms is muddied by the high level of comorbidity in this population (88-90). Around $73 \%$ of $\mathrm{CHR}$ individuals have at least one other Axis I disorder (89). Long-term studies show persistence of comorbid disorders such as mood (15-38\%), anxiety (5-16\%), substance use (11\%), personality disorders $(2.7 \%)$, and other diagnoses $(43-52 \%)(91,92)$. At a 6-year follow-up, approximately $56.8 \%$ of $\mathrm{CHR}$ patients endorsed at least one comorbid disorder and $61.5 \%$ of them reported continued comorbidity from baseline (91). Only a small group of CHR individuals (7-16\%) reported no comorbid diagnoses at baseline or follow-up $(91,92)$. Clearly, comorbidity is the rule and not the exception when dealing with EP symptomatology. Since up to $65 \%$ of CHR individuals do not go on to develop psychotic disorders within 3 years after initial CHR diagnosis, such subthreshold psychotic symptoms experienced may have responded to treatment, resolved over time, or may be better explained by another psychiatric diagnosis. In a strict sense, these non-converters may be considered "false positive" diagnoses regarding a pre-psychotic phase of illness. Thus, the CHR syndrome may best be understood as a mixture of individuals identified prior to the onset of psychosis, along with adolescents/young adults who experience subthreshold positive 
symptoms in the context of a primary mood, anxiety or PTSD. Any relationships to trauma must be understood in this context, given the extensive literature that links trauma to later mood and anxiety disorders. In this section, we examine the various comorbid disorders within the CHR and other psychotic disorders and their symptom interaction with CT.

\section{Mood/Anxiety Disorders}

Clinical high risk individuals with CT showed high comorbid $\operatorname{mood}(40-45 \%)$ and anxiety disorders $(15.3 \%)(5,42,93)$, as did CHR individuals with SLEs [i.e., major depressive disorder (13\%), bipolar disorder (8.7\%), dysthymic disorder (4.3\%), social phobia (17.4\%), generalized anxiety disorder (8.7\%), panic disor$\operatorname{der}(4.3 \%)]$ (57). However, a study on CHR samples was unable to show a relationship between CT and mood/anxiety disorders, possibly due to low sample size $(n=30)(56)$. Available studies on CHR and first-episode psychosis (FEP) individuals with CT show that both groups had higher rates of suicidal attempts, elevated rates of psychiatric hospitalization, and poorer clinical functioning $(3,59)$. Studies on individuals with schizophrenia suggest that CT is associated with increased severity of depression and anxiety disorders $(94,95)$. The small number of current findings related to comorbid mood and anxiety disorders among CHR groups with CT warrants additional research in this area to untangle whether trauma is specifically related to positive psychotic symptoms.

\section{Substance Use}

Despite high rates of comorbid substance use in CHR populations, particularly tobacco $(34.4 \%)$, alcohol (17-44\%), and cannabis (3-54\%) (96), there is currently limited research specifically focused on CHR individuals with trauma and substance use. However, there are well-documented links between trauma and substance use in the general population (97) and the role of substance use in triggering psychotic episodes $(98,99)$. While there is minimal support as of yet for the direct relationship between substance use and conversion to psychosis in the CHR group, there is stronger evidence for the relationship between substance use and increased severity of subthreshold psychosis symptoms among CHR individuals (96). School-aged youth showed an interaction effect between CT and cannabis use that accounted for $83 \%$ of their reported psychosis symptoms (100). Better understanding potential interactions between trauma and substance use as risk factors for psychosis is a critical need in the literature, as well as highly relevant to designing interventions for this population.

\section{Posttraumatic Stress Disorder}

Most critical to comorbidity issues in our review of trauma and the CHR syndrome is the presence of PTSD in this population. A multisite $\mathrm{CHR}$ study reported a significantly higher prevalence rate of current $(2.6 \%)$ and lifetime (4.1\%) formal PTSD diagnosis than in HCs (101). Specifically, CHR youth with a CT history demonstrates PTSD rates of $15.2 \%$ (3). Similar to mood and other anxiety disorders, comorbid PTSD diagnoses with FEP individuals who have a trauma history are associated with longer treatment duration and more intensive treatment to address all presenting symptoms (3). A meta-analysis indicated that individuals who suffer from comorbid psychosis and PTSD endorse symptoms of faulty cognitive appraisals, feelings of helplessness, and lack of control (75). These are, of course, important targets for treatment with individuals who have comorbid PTSD and psychosis, and may be relevant for CHR treatment.

\section{Differential Diagnosis of PTSD and CHR Status}

A common referral question posed by clinicians seeking evaluation for a consumer asks- "Is it trauma or EP?" Indeed, the symptoms associated with PTSD can create diagnostic uncertainty. There are a number of similarities between the symptoms of PTSD and psychosis (102). Hallucinations in psychosis are analogous to the experience of flashbacks and intrusive images and bodily sensations associated with PTSD as they both present in visual, auditory, or tactile modalities and are usually experienced as distressing and unbidden. Suspiciousness in psychosis resembles the hypervigilance in PTSD and avoidance behaviors, which are a hallmark of PTSD and can be similar to safety-seeking behaviors or negative symptoms in psychosis. Hallucinations in an adolescent sample were found to be highly prevalent in both PTSD and psychotic disorders, and the hallucinations of psychosis and PTSD could not be differentiated in terms of content, modality, location, or form $(103,104)$.

It may also pose additional difficulties when evaluating individuals with more severe symptoms. Data from the U.S. National Comorbidity Survey Part II indicated that all of the positive psychotic symptoms examined in the sample were more likely to be endorsed by respondents who met diagnostic criteria for PTSD than those without PTSD (105). A dose-response relationship was also found, such that with more PTSD symptoms endorsed, the higher likelihood for experiencing both symptoms of paranoia and hallucinations. Among the psychotic symptoms, auditory hallucinations had the greatest odds ratios with lifetime PTSD diagnosis. Several studies on non-clinical, community samples suggest that CT is a strong risk factor for visual, auditory, and tactile hallucinations $(106,107)$. Data from the National Comorbidity Survey indicated that a history of childhood rape was significantly associated with auditory hallucinations in a non-clinical adult (Age $\mathrm{M}=32$ years, $\mathrm{SD}=10.59$ ) sample (107).

Despite the substantial similarities, one study of adolescents suggests that command hallucinations and derogatory themes were more common in PTSD and were associated with higher emotional distress, self-injury, and suicidal ideation, compared to hallucinations in schizophrenia (103). Furthermore, the presence of PTSD in children and adolescents has been noted to confer a substantial likelihood of disturbances of reality testing. Maltreated and traumatized children with a PTSD diagnosis are more likely than children with a history of trauma with no PTSD diagnosis to also meet criteria for a brief psychotic episode or unspecified psychotic disorder with symptoms analogous to the CHR syndrome (108). However, children with PTSD rarely exhibited full-blown delusions or illogicality. Thus, perceptual disturbances and suspiciousness may be present both in the CHR syndrome and in PTSD while other types of delusional thinking, cognitive disorganization, and negative symptoms (differentiated 
from mood disturbance or avoidant behaviors) may be more specific to psychotic disorders.

\section{MECHANISMS OF TRAUMA AND STRESS IN THE CHR POPULATION}

Multiple models have been cited to explain the link between trauma and later psychosis, including the stress-vulnerability and stress-sensitivity hypotheses, with emphases on both cognitive processes and neurobiological mechanisms (e.g., the hypothalamic-pituitary-adrenal axis). Consistent with a gene-environment interaction model, trauma history appears to contribute to psychosis in adulthood somewhat independent of genetics (109). A recent gene-environment interaction study supports the idea that genes associated with schizophrenia lead to changes in not only dopamine but also serotonin signaling pathways in the brain, thus suggesting an "affective pathway" to psychosis (110). Below, we address models that have been referenced in previous works to explain the potential interplay between trauma, stress, and psychosis. Following the discussion of currently identified relationship models of trauma and psychosis, we propose our own comprehensive model that conceptualizes a cyclical relationship between trauma and psychosis risk.

\section{Stress-Vulnerability Model}

In an effort to understand the mechanism through which trauma and stress may lead to psychosis, Zubin and Spring (111) proposed the stress-vulnerability model. This model posits that individuals possess a genetic or biological vulnerability to psychosis that can withstand a certain amount of stressors due to genes and other biological risk factors. However, once the stress threshold is surpassed, psychosis may be at higher risk of development (see Figure 1) (111). From this perspective, the experience of trauma increases one's experienced stress and, therefore, leaves them at greater susceptibility to experiencing psychopathology. One way this has been examined biologically is through research on the functioning of the hypothalamic-pituitary-adrenocortical (HPA) axis (see Figure 2), one of the primary stress response systems in the human body.

\section{Stress-Sensitization Model}

The impact of stress on psychopathology has also been discussed in the context of stress sensitization (112). The origins of this concept come from animal models that indicated individual differences in stress-sensitivity and -reactivity due to interactions between genes and environments. Similar to the stress-vulnerability model, the stress-sensitization theory hypothesizes that for a person to experience their first psychiatric illness, they may have a biological vulnerability, and then need to experience a major stressor. After the initial emergence of psychopathology, vulnerability increases, requiring less stress for the person to develop recurrent or more severe psychiatric issues (113). Thus, experience of CT may render an individual more susceptible to psychosis triggered by later stressors. Walker and Diforio (114) describe the connection of behavioral and biological stressors in

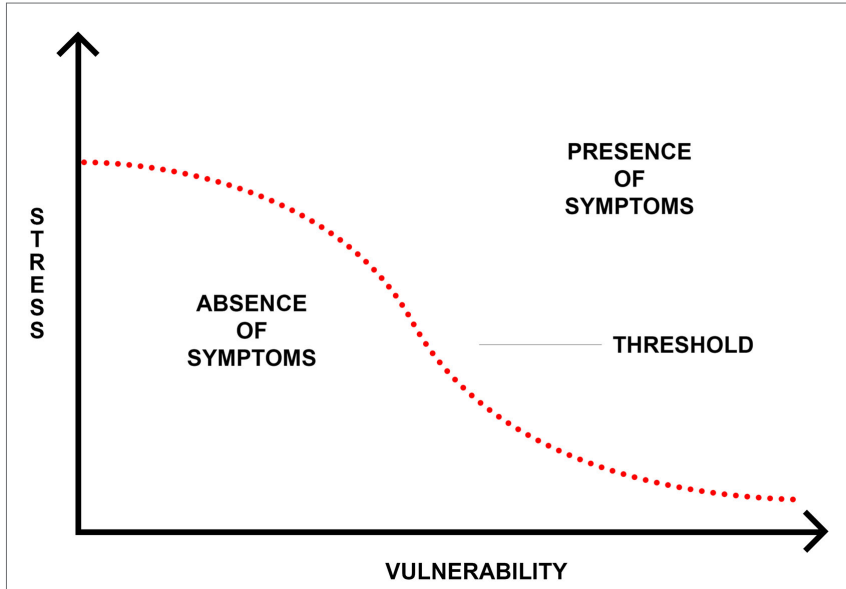

FIGURE 1 | Stress-vulnerability model (111)

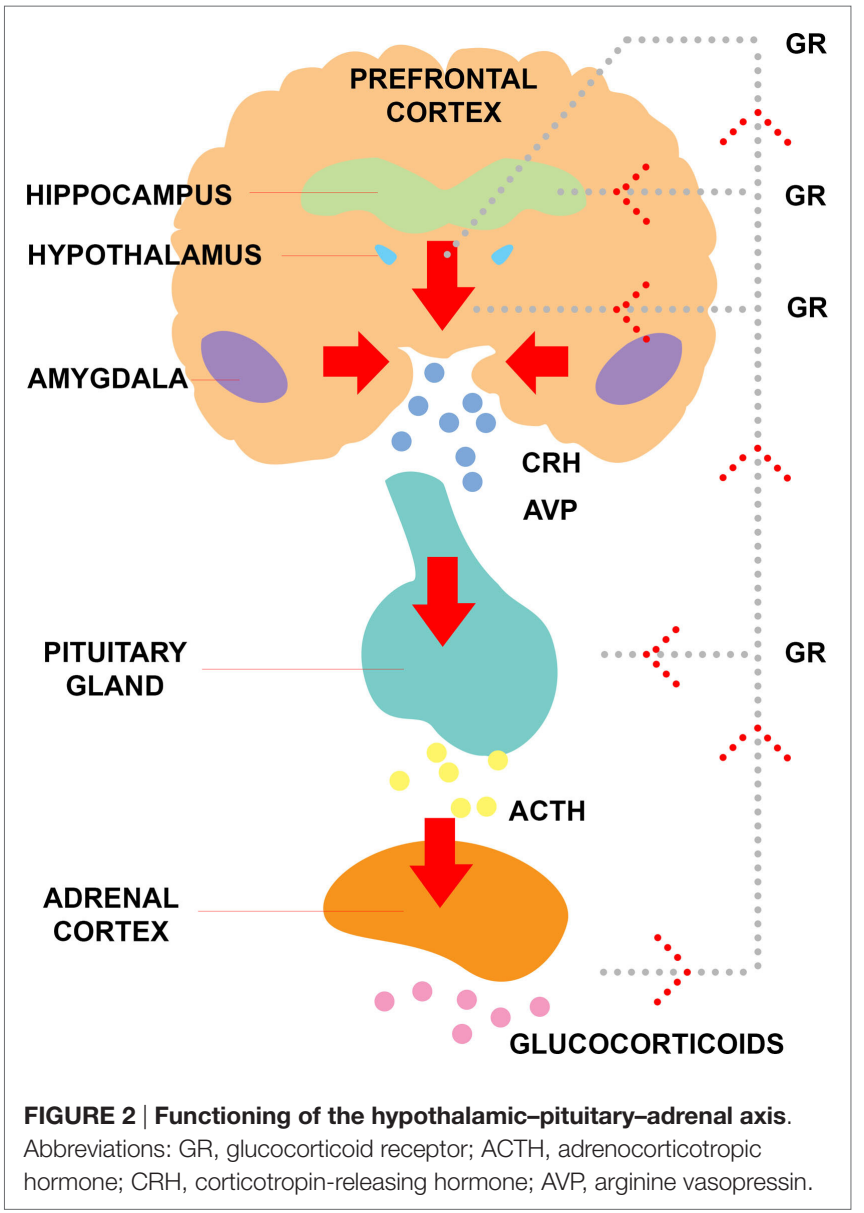

psychosis and how dysregulation of stress response in both of these capacities overtime can create even greater disturbances in the HPA axis, thereby creating even more damaging effects on one's functioning. Support for the concept of a dysregulated response to stress following trauma can be seen in other mental health conditions. In a study of 18,713 individuals without a 
psychiatric diagnosis prior to the September 11 attack in the US, those who reported a CT history and were either directly or indirectly affected by the attack were at significantly greater risk of experiencing an internalizing disorder and were more vulnerable to elevated stress in comparison to those that did not report CT (115). Within the CHR population, the stress-sensitization model has never been formally tested; that is, no study has examined the possibility of an interaction between CT or SLEs and raising the risk for psychosis onset. A very large sample would be required to test an interaction model to predict conversion to psychosis, which one would only expect for up to a third of CHR individuals. However, partial behavioral evidence for stress sensitization was reported from the NAPLS study, in which CHR individuals who converted to psychosis not only reported more SLEs but also experienced higher levels of self-reported stress than CHR participants whose symptoms remitted. Additionally, those who rated more SLE also indicated higher stress from daily hassles (116). However, they did not examine any relationship of CT to SLE response. We have begun to investigate this possible interaction in our own work as described below.

\section{Dysregulated Stress Response}

Cortisol is a biological stress marker, the final product of activation of the HPA axis in response to stress and can be obtained through plasma, saliva, and urine (117). Cortisol has a standard diurnal rhythm that can be assessed when samples are collected throughout the day (118). In addition to quantifying its daily cycle, stress reactivity can be measured when cortisol is measured in saliva samples that have been collected when a person is undergoing a stressful task (119). Therefore, dysregulation of the HPA axis can be evaluated globally to address the underlying vulnerability to stress, and locally, sensitivity can be evaluated in response to a specific stress task. Findings within the schizophrenia population indicate elevated cortisol (a physiologic measure of stress responsivity) in many individuals with psychosis $(120,121)$, with some variable results indicating both hyper- and hypo-function of the HPA axis (122). Some of the heterogeneity in results could be due to the presence of antipsychotic medication, which has shown to decrease cortisol levels $(122,123)$ or potentially to the experience of trauma.

\section{Trauma and the HPA Axis}

There is currently some evidence for the impact of trauma on the development of altered stress responses and psychopathology. Indeed, research has shown blunted cortisol secretion in patients with PTSD (124), and in women with a history of sexual trauma (125), as well as for patients with schizophrenia who reported CT. In a study of 14 individuals who met diagnostic criteria for DSM-IV schizophrenia, those who reported moderate to severe CT experiences had lower diurnal cortisol secretion, especially within the first hour of the waking, whereas those without the experience of CT exhibited higher levels of cortisol throughout the day (126). Following the same pattern, Phassouliotis and colleagues (127) found lower basal cortisol levels, in a sample of first-episode patients who reported significantly higher rates of CT than HC. However, due to the small sample size, within-group comparisons of first-episode patients with and without CT could not be explored. Within the CHR population, this theory has had a lack of attention, but one study has supported the idea. Although trauma was not explicitly assessed, decreased cortisol secretion as a response to Trier Social Stress Test administration was found in a small sample of CHR individuals who also reported higher levels of chronic stress compared to HCs (119). Further research evaluating CT history explicitly within the CHR population is necessary to understand its impact on cortisol secretion.

Evidence suggests that psychosocial stress activates the HPA axis and, in turn, the dopamine and serotonin systems, where exaggerated effects have been observed in individuals who experienced childhood adversity (110, 128). Neuroimaging studies (i.e., magnetic resonance imaging; functional magnetic resonance imaging; positron emission tomography; diffusion tensor imaging; multimodal) have revealed that in those $\mathrm{CHR}$ individuals who converted to psychosis, functional changes in striatal dopamine synthesis and release were observed (129-131). In addition, Oswald and colleagues (132) found that perceived stress partially mediated the association between childhood adversity and ventral striatal dopamine responses. A full exploration of the potential neurobiological mechanisms linking trauma and psychosis are beyond the scope of this paper, but we provide these examples of one possible relationship and highlight the need for further research in this area.

Overall, a majority of studies has demonstrated abnormalities in cortisol secretion in CHR samples compared to HC (133). In a large sample of $256 \mathrm{CHR}$ patients and $141 \mathrm{HC}$, the CHR group exhibited significantly higher mean diurnal salivary cortisol levels (134). Participants who converted to full psychosis in the CHR group had higher mean daily cortisol levels than those who remitted. However, the specificity of this result to psychosis is unclear, as well as whether it is a cause or consequence of attenuated psychosis. It may be related to the high rates of mood and anxiety disorders in this group rather than be central to psychosis, specifically. Its relative contribution to psychotic transition in the context of other significant risk factors is also not yet fully understood. Additional research that follows HPA axis functioning overtime and relates it to symptom expression and other biomarkers, such as genetics and neuroimaging, are critical to understanding the role it may (or may not) play in psychosis risk. A dysregulated stress response with altered cortisol secretion may be evidence of a subgroup of CHR individuals who experience an affective/stress pathway to psychosis, and thus moderating the stress response at a biological or behavioral level could be an important target for intervention in those with a demonstrated dysregulated response.

\section{Cognitive Mechanisms}

Several cognitive mechanisms may explain the associated link between trauma and psychotic disorders. For instance, it has been suggested that early adversity may lead to the formation of negative schemas of the self, others, and the surrounding environment (135). Such negative views may eventually contribute to greater external locus of control (54) and increased symptoms of suspicious or paranoia (136). CT may be associated with faulty responses to environmental stimuli, such as informational processing bias for negative or irrelevant stimuli $(137,138)$. Such 
focus on irrelevant or what may appear to be threatening stimuli has been thought to lead to reasoning bias (e.g., jumping into conclusions) $(136,139)$ and paranoid thinking $(140)$. For a more detailed overview of cognitive and neurobiological mechanisms involving trauma and psychosis, we refer the reader to a recent review by Gibson and colleagues (141).

\section{The Cycle of Trauma, Psychosis, and Future Risk of Trauma}

To comprehend the impact of CT and SLE on the development of psychosis, the synthesized findings point to the cyclical nature of trauma, psychosis risk, and increased vulnerability for future traumatic experiences. However, given the current weak findings associating SLE with CHR transition to psychosis, our conceptualized model focuses primarily on CT. Individuals exposed to CT are at elevated risk for abnormal childhood development in terms of neurocognitive, social, and emotional functioning. Depending on the form and severity of CT, some may have a more negative impact on learning and development. For instance, exposure to physical abuse or witness of domestic violence can create globally negative views of the self, others, and the world (142). Maladaptive behaviors (e.g., non-suicidal self-injury, suicidal behaviors, aggression), poor coping skills, and impaired emotional regulation may also arise out of CT experiences, increasing one's risk for developing mood and anxiety disorders (143). These same behaviors can result in poorer role and social functioning overtime (e.g., bullying, increased peer isolation), thus decreasing protective factors, such as social support and adaptive problem-solving skills. Several studies have also highlighted that the sole experience of trauma does not predict poor clinical functioning and $\mathrm{CHR}$ status $(34,52)$. Instead, as explained by the stress-sensitivity model, one's trauma history creates an initial level of elevated vulnerability for later psychopathology, such as SMI. Other risk factors (e.g., genetic, environmental) may add or interact with trauma to confer increased risk for psychosis. While the current evidence does not support SLE as a trigger for psychosis onset, they do lead to increased levels of depression in both episodes and severity (143). Severe mood disorders that are characterized with psychotic features are often more difficult to treat (144, 145). Thus, the dose-response relationship suggests that with increased CT experiences, the risk for later psychosis becomes greater.

Unfortunately, the negative impact of CT does not end at the onset of psychotic illness. For CHR individuals who endorsed CT, the emergence of psychosis creates a string of increased vulnerability for future traumatic experiences. CHR individuals with CT who go on to full psychosis conversion tend to have poor long-term functioning outcomes (61). In general, increased psychosis risk is associated with a decline in global functioning (e.g., social, role), emergence of comorbid disorders (e.g., depressed mood and anxiety disorders, PTSD, substance use), poor treatment engagement, and increased maladaptive coping skills and behaviors (16-19). The influence of CT further adds to the complexity of their symptom presentation and severity. As a result, the cascade of abnormal development and increased psychopathology leads to the resurgence of future vulnerability to other trauma.

The trauma-psychosis risk relationship postulates that following an initial traumatic experience, an individual experiences an abrupt change in their normal developmental course, is weakened in various areas of functioning, and therefore, is made more vulnerable moving forward in development. Based on the interaction between an individual's genetic foundation and their interaction with environmental stressors, including increased stress sensitization, the risk of psychosis conversion escalates. With the onset of full psychosis, individuals are further weakened in their ability to adaptively respond to stressful situations and adverse events moving forward, leading to increased risk of experiencing additional future trauma/SLEs. Nevertheless, the findings which highlight no associations between trauma and transition to full psychosis offer hope that there may be strong protective factors that can be bolstered during treatment of early subthreshold psychotic symptoms or that there may be additional risk factors that can help identify a subgroup of CHR individuals at particular risk for worsening psychosis related to CT.

\section{TRAUMA ASSESSMENT IN THE CHR SYNDROME}

To better understand the role of trauma in the CHR syndrome, current methods of trauma assessment must be harmonized. Although they are used regularly with individuals with psychosis or the CHR syndrome, no existing trauma or SLE measures have been developed or validated specifically with these populations. The National Child Trauma Stress Network (146) and the American Academy of Child and Adolescent Psychiatry (147) provide guidelines on the appropriate assessment and treatment of children and adolescent who may have experienced trauma. These guidelines stress the need to briefly screen all children in a given setting for the experience of traumatic events and, in the presence of a positive screen, to follow up with a more detailed assessment in order to appropriately guide treatment planning.

Trauma experiences and associated clinical consequences can be identified through a variety of methods. Brief self-report screening questionnaires retrospectively assess for the occurrence and reaction to a variety of traumatic events. Brief screening measures for assessing only exposure to traumatic events include the Brief Trauma Questionnaire (148) and the CTQ (149). Measures examining both the experience of trauma and its psychological impact (e.g., assesses symptoms and distress) include the Trauma Symptom Checklist for Children (150) and the Child Posttraumatic Symptom Scale (151). The UCLA PTSD Reaction Index for DSM-IV (152) is an example of a combined measure that starts with a brief questionnaire to assess for a history of traumatic events, which is then followed by a semi-structured interview to determine distress and impact of those events to support a diagnosis of PTSD. Some measures also include a collateral informant report, such as the Trauma Symptom Checklist for Young Children (153). Finally, semi-structured diagnostic interviews such as the Structured Clinical Interview for DSM-IV Axis-I Disorders (SCID-I) (154) and the Kiddie Schedule for 
Affective Disorders and Schizophrenia (155) include sections to assess for a history of traumatic events and their clinical sequelae. Measures most commonly used in CHR research studies are the CTQ, Trauma History Screen, and the CT and Abuse Scale. For a comprehensive list of trauma experience and symptom measures, please refer to the National Child Traumatic Stress Network and the American Academy of Child and Adolescent Psychiatry resources $(146,147)$.

While various measures of traumatic experiences and SLEs are available, there may be concerns about using them with CHR individuals. For instance, if there are concerns about early trauma experiences being distorted by the delusional thinking (e.g., suspiciousness), collateral reports from family, previous treatment providers, and school staff can clarify the validity of the individual's reported experience. Conversely, it may be difficult to determine if certain attenuated symptoms (e.g., suspiciousness) are associated with reality-based experiences of victimization and better accounted for by a trauma reaction than a psychoticspectrum symptom. However, a previous study that has examined the reliability of reported CT experiences by individuals with psychotic disorders found that they were retrospectively accurate and stable over time irrespective of current psychopathology (156). Patients may tend to underreport CT while in treatment for psychosis and could be more forthcoming when experiencing more severe psychotic symptoms. Nevertheless, studies have tackled this issue by enforcing other measures for additional precaution. A UK study on a national sample of $(n=2,172)$ 12-year-old twin children showed that research protocol can easily be structured to determine credibility of children's reporting in clinical interviews, such as enforcing a rating system that codes from 0 (i.e., not a symptom), 1 (i.e., a likely symptom), to 2 (i.e., definite symptom); and enlisting the clinical judgment of various professionals who are familiar with the CHR group/symptoms within the psychosis spectrum or whose area of specialization is with youth (41). Additionally, clinicians may worry that discussing trauma as part of an evaluation can trigger worsening of psychotic symptoms, which may lead to avoidance of appropriate assessment. Contrary to this belief, research suggests that appropriate and sensitive evaluation of trauma does not increase subjective distress $(157,158)$.

One significant challenge of concordant trauma and SLE assessment in this population is that the age of individuals often ranges from 12-30, and instruments are often designed for either children, adolescents, or adults. The types of trauma and SLEs experienced by these different age groups vary considerably, with school and family-related stressors (e.g., divorce of parents) relevant for children and work and romantic relationship-related stressors (e.g., one's own divorce) more relevant for young adults. The measurement of trauma and stressors overtime in the same individual creates challenges in the consistent use of instruments. While a variety of appropriate measures exists to aide in the identification of trauma, there is currently no standardized trauma evaluation protocol for CHR groups as part of research or clinical practice. This lack of detailed information related to trauma or SLE that can be compared across clinics and research precludes our ability to effectively target treatment or elucidate relationships in research.

\section{CHR and Trauma Interventions}

Given the high prevalence and relevance of trauma in the CHR syndrome, which we have outlined above, the next step is translating this knowledge to improve interventions for this population. Trauma and psychosis are two of the most difficult clinical symptoms to target and manage in psychiatric treatment; combined, they are considered by most mental health providers to be one of the most complex forms of mental illness, usually requiring a greater level of care. Typically, when individuals present to clinical treatment settings for either symptoms of trauma or psychosis, they are often referred to clinics with an expertise in one of the two areas of concern because few programs provide integrated care for both issues (159). Consequently, there is a growing need for treatment settings that provide clinical expertise on both trauma and psychosis. Given the complex interplay of symptoms, the current model of the trauma-psychosis cycle (see Figure 3) suggests that CHR individuals who present with trauma history do not share the same expected course of treatment and recovery as those without a history of trauma. As shown by Cragin and colleagues (159), there is a growing need to address trauma in EP care. Recent research on trauma treatment in psychosis has shown the impact of prolonged exposure, an evidence-based trauma treatment, on reducing trauma symptoms and psychosis in individuals with chronic schizophrenia and comorbid trauma (160). However, many clinicians are concerned that addressing trauma in treatment may trigger worsening of psychosis (161). Given the lack of attention to trauma-focused treatments in psychosis, it is no surprise that even less has been developed in EP, despite the preponderance of first episode and CHR individuals who endorse CT. To date, no clinical trials have been published evaluating interventions for trauma in CHR youth. Currently, many CHR clinics utilize treatment based on cognitive-behavioral therapy (CBT) methods for individual treatment and family-based treatments [e.g., multi-family group (MFG) or functional family therapy (FFT)] to address social stress and support. The addition of components from Trauma-Focused Cognitive Behavioral Therapy (TF-CBT) represent a potential approach to providing trauma-informed care for CHR individuals that is consistent with prominent treatment models for this population. Both CBTp and TF-CBT start with providing psychoeducation and enhancing coping skills, then introduce methods of cognitive coping, before providing opportunities to address psychotic symptoms, or trauma symptoms via exposure. Similar to MFG and FFT, TF-CBT also integrates family members to maintain support for the individual and ensure generalization outside of the therapeutic context. While TF-CBT is a promising approach for the CHR population, it has not yet been fully developed nor evaluated. This is a critical area of future research.

\section{IMPLICATIONS AND FUTURE DIRECTIONS}

Overall, recent findings continue to provide supporting evidence for higher rates of trauma among CHR individuals compared to HC, consistent with Kraan and colleagues (5). Emerging studies 


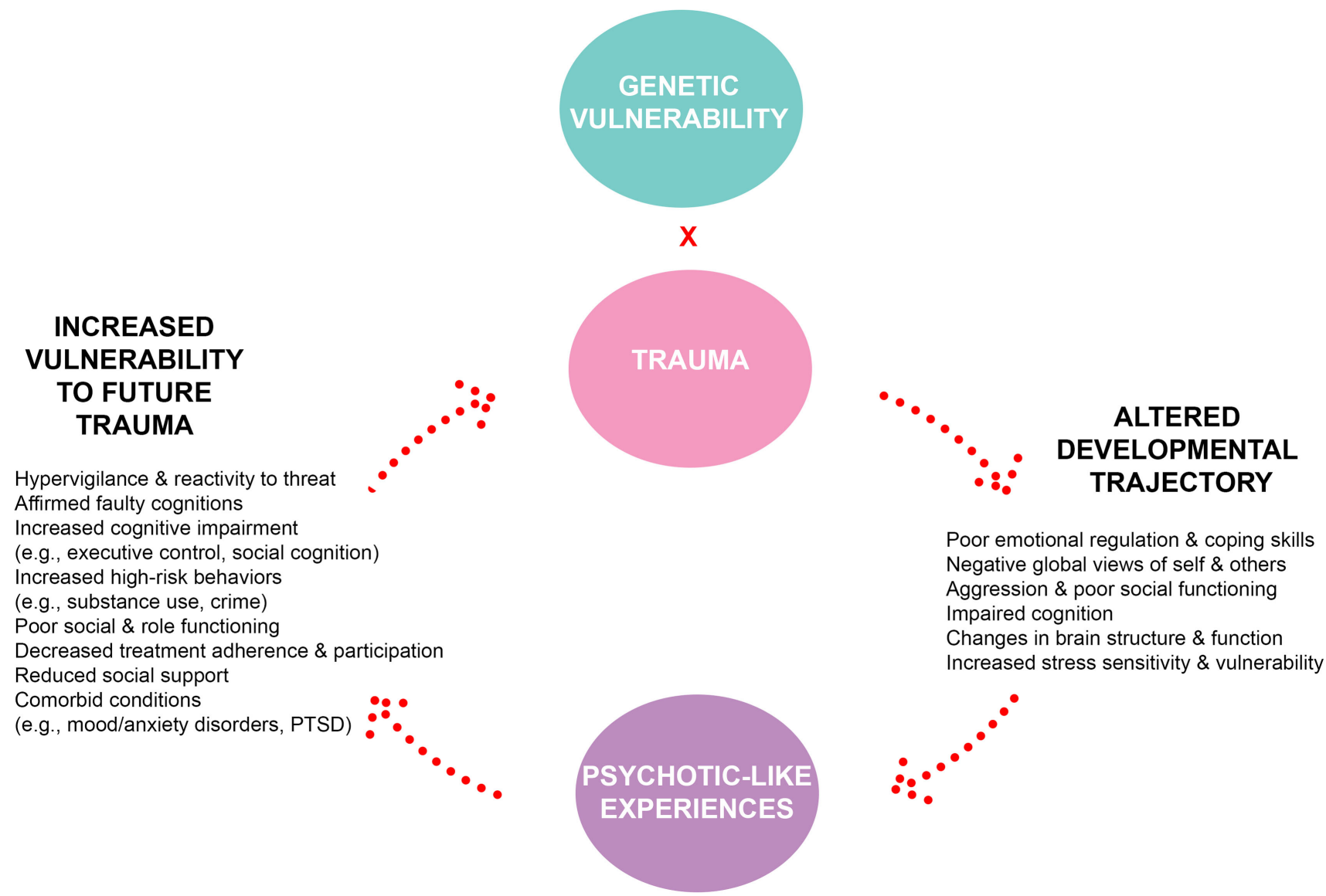

FIGURE 3 | The cycle of trauma, psychotic-like experiences, and vulnerability.

continue to show a strong relationship between CT and severity of psychosis symptoms in the CHR population $(34,45,51)$. Studies of CHR individuals with CT also repeatedly demonstrate a negative relationship with cognitive, clinical, and social functioning outcomes overtime $(34,59)$. Trauma appears to predict conversion to psychosis, but may not function independently of other known risk factors such as more severe positive symptoms, cognition, and functioning (16). While CHR individuals may demonstrate heightened stress reactivity at the clinical and biological levels $(119,134)$, the role of SLEs in triggering transition to psychosis has not been clearly substantiated. As a result, the current proposed model of the trauma-psychosis cycle (Figure 3) focuses solely on CT and not SLE. However, SLE may be an important area to consider when refining the proposed trauma-psychosis model when additional studies provide a richer understanding of its influence on psychosis risk. Finally, the mechanisms underlying the relationship of trauma to psychosis onset in CHR individuals are not fully understood, although there is some evidence for both cognitive and biological (HPA axis, gene-environment interaction) models (111, 141). Most importantly, no appropriate interventions have been developed and validated specifically for trauma in CHR individuals, despite an enormous need for such an approach. The overall findings suggest that the study of trauma, stress, and psychosis risk is still in its early stages and requires continued work. Several suggestions are provided to further research and clinical interventions in addressing the role of trauma and SLEs in psychosis among CHR individuals.

\section{Recommendations for Future Research}

First, larger sample sizes in CHR trauma studies would support stronger inferences in research findings via increased statistical power that allows for testing of interaction models, mechanistic mediation models, and simultaneous testing of multiple predictors of outcomes. Adequate representation of minority groups and more international research would help to evaluate potential demographic differences. Second, inclusion of a psychiatric control group (e.g., mood and anxiety disorders without psychotic-like experiences) would prove useful in delineating what is unique to CHR individuals and what is shared with other symptom domains. Third, a standardized measure, validated for the adolescent/young adult population would help to compare across studies and assess cohorts longitudinally. The measure should assess both the number and age of occurrence of traumatic events in order to investigate whether there is a "critical period" for CT and to test stress-sensitization models. 
Moving forward, the research definitions for trauma types and SLEs should be consistent and specific in order to facilitate comparison of research results across studies. For instance, some measures assess narrow definitions of trauma while other "trauma" measures also include events that are less severe and are better categorized as SLE. As another example, there is great disparity between individuals and families concerning the definition of childhood physical abuse. Researchers would benefit by providing participants with an operational definition of childhood physical abuse to help increase their responses' internal validity. Similarly, differences in the definitions of abuse across cultures should also be investigated to clarify the constructs that are measures as part of a study. In addition, the current studies examined suggest that sexual abuse history is a prominent area that demands greater focus and consideration in CHR population research, given the psychological cost of illness that may follow. Based on the current review's proposed conceptualization of trauma and psychosis risk occurring in a cyclical and repeated pattern, it is suggested that future studies on CHR individuals should consider examining the influence of complex trauma (i.e., multiple types of trauma) on psychosis risk. Additional variables to consider would be the severity and duration of trauma experiences as well as differentiating between a single traumatic event and chronic abuse, with the latter potentially conferring greater risk. Furthermore, research should delve deeper into gender differences among CHR individuals with trauma, given evidence of differential rates and effects in psychosis $(42,53)$.

\section{Recommendations for Treatment and Interventions}

For clinical recommendations and improved delivery of service, it would be important for clinicians to determine a treatment plan that considers both trauma and psychosis symptoms. A decision-tree process that decides primary areas to initially target would be helpful and should be a focus of future clinical research (90). Clinicians should be able to determine whether trauma is a significant centerpiece of the presenting problem or a complicating factor that aggravates the individual's psychosis symptoms. Case conceptualizations should also consider modifications of standard treatment when necessary in order to better address the client's needs. During intake and clinical evaluations, it may be useful to create a timeline of CHR individual's trauma and SLEs in relation to their other clinical symptoms and associated functional decline. This documented information may prove imperative use for case conceptualization and treatment planning. In reference to the trauma-psychosis cycle (Figure 3), the timeline of events in a CHR individual's life may give helpful information into the nature of their trauma history, its severity, and the level of treatment required.

The accumulated knowledge on trauma and psychosis thus far highlights that children and youth who experience CT and/ or SLEs should be referred for immediate clinical evaluation and intervention. In particular, youth who report early bullying experiences should be taken seriously, as it can be one of the earliest forms of social stress that persists and influences various domains of functioning and well-being. Individuals experiencing psychotic-like symptoms should be encouraged to seek treatment to boost their cognitive and behavioral coping skills in order to help them combat increased vulnerability to future trauma. Families and parents have a pivotal role in increasing the effectiveness of any treatment intervention. As demonstrated by the trauma-psychosis cycle (Figure 3), the experience of trauma can be pervasive and persistent. Clinicians are strongly urged to involve parents, family members, or other significant people in treatment with CHR youth dealing with trauma and psychosis to enhance their social support system and buffer them against additional stressors.

A particular challenge is that many clinicians working with adolescents have not received sufficient training regarding psychotic-spectrum conditions, and specialists in EP may not have sufficient training in trauma treatment (159). Broad availability of training across clinical degree programs in the US regarding assessment and treatment of psychosis would help to improve community providers' accurate detection of potential CHR syndromes in traumatized youth. Further, training for coordinated specialty care programs that treat EP should include training modules on the appropriate assessment and treatment of trauma.

As advocated by previous research $(61,142)$, a standard protocol for CT or SLE assessment during all initial patient evaluations should be used in pediatric and behavioral health settings. Due to the sensitive nature of the assessment questions, clinicians and other medical providers should recognize the appropriate format of assessing trauma history in youth (i.e., separately or with their parents/caregivers in the room). Akin to training on suicide risk screening, clinical staff should be knowledgeable on how to identify and assess for trauma when working with $\mathrm{CHR}$ youth.

Most importantly, based on the current collective knowledge on trauma and stress in EP, we conclude that evidence-based treatments addressing trauma symptomology in the CHR population is desperately needed. Without a targeted and evidence-based treatment for a large number of CHR youth with trauma history and/or SLE, current interventions may not always be successful in impacting their illness trajectory. Yet, the preliminary outcomes from current studies show promising evidence; with improved understanding of the mechanisms that perpetuate the cycle of trauma among CHR individuals, we can promote resilience and mitigate the vulnerability of $\mathrm{CHR}$ individuals to developing a psychotic disorder and improve their chances of recovery from the CHR syndrome.

\section{AUTHOR CONTRIBUTIONS}

All the authors participated in the writing of the manuscript. DM was the lead author and primary writer. SC and AY contributed in the writing of Section "Mechanisms of Trauma and Stress in the CHR Population." LK conducted a wide literature review of CHR studies and contributed in the writing of Section "Trauma Experiences in the CHR Population." SY coauthored Section "Trauma Experiences in the CHR Population" and 
Section "Recommendations for Future Research." BS coauthored the "Differential Diagnosis of PTSD and CHR Status" subsection. TN coauthored Sections "Trauma Assessment in the CHR Syndrome" and "Implications and Future Directions" and provided overall feedback on the manuscript. RL was the senior author of the manuscript and provided overall guidance and feedback on topic of trauma, stress, and psychosis risk

\section{REFERENCES}

1. Aakre JM, Brown CH, Benson KM, Drapalski AL, Gearon JS. Trauma exposure and PTSD in women with schizophrenia and coexisting substance use disorders: comparisons to women with severe depression and substance use disorders. Psychiatry Res (2014) 220(3):840-5. doi:10.1016/j.psychres.2014.10.004

2. Sahin S, Yuksel C, Guler J, Karadayi G, Akturan E, Gode E, et al. The history of childhood trauma among individuals with ultra high risk for psychosis is as common as among patients with first-episode schizophrenia. Early Interv Psychiatry (2013) 7(4):414-20. doi:10.1111/eip.12022

3. Conus P, Cotton S, Schimmelmann BG, McGorry PD, Lambert M. Pretreatment and outcome correlates of sexual and physical trauma in an epidemiological cohort of first-episode psychosis patients. Schizophr Bull (2010) 36(6):1105-14. doi:10.1093/schbul/sbp009

4. Kilcommons AM, Morrison AP. Relationships between trauma and psychosis: an exploration of cognitive and dissociative factors. Acta Psychiatr Scand (2005) 112(5):351-9. doi:10.1111/j.1600-0447.2005.00623.x

5. Kraan T, Velthorst E, Smit F, de Haan L, van der Gaag M. Trauma and recent life events in individuals at ultra high risk for psychosis: review and meta-analysis. Schizophr Res (2015) 161(2-3):143-9. doi:10.1016/j.schres.2014.11.026

6. Gerrity E, Folcarelli C. Child Traumatic Stress: What Every Policymaker Should Know. Los Angeles, CA; Durham, NC: National Center for Child Traumatic Stress (2008).

7. Miller TJ, McGlashan TH, Woods SW, Stein K, Driesen N, Corcoran CM, et al. Symptom assessment in schizophrenic prodromal states. Psychiatr Q (1999) 70(4):273-87. doi:10.1023/A:1022034115078

8. Yung AR, Yuen HP, McGorry PD, Phillips LJ, Kelly D, Dell'Olio M, et al. Mapping the onset of psychosis: the comprehensive assessment of at-risk mental states. Aust NZ J Psychiatry (2005) 39(11-12):964-71. doi:10.1080/j.1440-1614.2005.01714.x

9. Fusar-Poli P, Cappucciati M, Rutigliano G, Lee T, Beverly Q, Bonoldi I, et al. Towards a standard psychometric diagnostic interview for subjects at ultra high risk of psychosis: CAARMS versus SIPS. Psychiatry J (2016) 2016:7146341. doi:10.1155/2016/7146341

10. Gross G, Huber G, Klosterkötter J, Linz M. Bonner Skala für die Beurteilung von Basissymptomen Bonn Scale for the Assessment of Basic Symptoms Manual, Kommentar, Dokumentationsbogen. New York: Springer-Verlag (1987).

11. Klosterkotter J, Hellmich M, Steinmeyer EM, Schultze-Lutter F. Diagnosing schizophrenia in the initial prodromal phase. Arch Gen Psychiatry (2001) 58(2):158-64. doi:10.1001/archpsyc.58.2.158

12. Fusar-Poli P, Bonoldi I, Yung AR, Borgwardt S, Kempton MJ, Valmaggia L, et al. Predicting psychosis meta-analysis of transition outcomes in individuals at high clinical risk. Arch Gen Psychiatry (2012) 69(3):220-9. doi:10.1001/ archgenpsychiatry.2011.1472

13. Cannon TD, Cadenhead K, Cornblatt B, Woods SW, Addington J, Walker E, et al. Prediction of psychosis in youth at high clinical risk: a multisite longitudinal study in North America. Arch Gen Psychiatry (2008) 65(1):28-37. doi:10.1001/archgenpsychiatry.2007.3

14. Lichtenstein P, Yip BH, Bjork C, Pawitan Y, Cannon TD, Sullivan PF, et al. Common genetic determinants of schizophrenia and bipolar disorder in Swedish families: a population-based study. Lancet (2009) 373(9659):234-9. doi:10.1016/S0140-6736(09)60072-6

15. Kendler KS, Diehl SR. The genetics of schizophrenia: a current, geneticepidemiologic perspective. Schizophr Bull (1993) 19(2):261-85. doi:10.1093/ schbul/19.2.261

16. Cannon TD, Yu C, Addington J, Bearden CE, Cadenhead KS, Cornblatt $\mathrm{BA}$, et al. An individualized risk calculator for research in prodromal psychosis. Am J Psychiatry (2016) 173(10):980-8. doi:10.1176/appi.ajp.2016. 15070890 in CHR group. All authors approved the final version of the manuscript.

\section{FUNDING}

No funding source is associated with the current manuscript submission.

17. Fusar-Poli P, Borgwardt S, Bechdolf A, Addington J, Riecher-Rossler A, Schultze-Lutter F, et al. The psychosis high-risk state: a comprehensive state-of-the-art review. JAMA Psychiatry (2013) 70(1):107-20. doi:10.1001/ jamapsychiatry.2013.269

18. Marshall C, Deighton S, Cadenhead KS, Cannon TD, Cornblatt BA, McGlashan TH, et al. The violent content in attenuated psychotic symptoms. Psychiatry Res (2016) 242:61-6. doi:10.1016/j.psychres.2016.05.005

19. Schmidt A, Cappucciati M, Radua J, Rutigliano G, Rocchetti M, Dell'Osso L, et al. Improving prognostic accuracy in subjects at clinical high risk for psychosis: systematic review of predictive models and meta-analytical sequential testing simulation. Schizophr Bull (2017) 43(2):375-88. doi:10.1093/schbul/ sbw098

20. Simon AE, Borgwardt S, Riecher-Rossler A, Velthorst E, de Haan L, FusarPoli P. Moving beyond transition outcomes: meta-analysis of remission rates in individuals at high clinical risk for psychosis. Psychiatry Res (2013) 209(3):266-72. doi:10.1016/j.psychres.2013.03.004

21. Nelson B, Yuen HP, Wood SJ, Lin A, Spiliotacopoulos D, Bruxner A, et al. Long-term follow-up of a group at ultra high risk ("prodromal") for psychosis: the PACE 400 study. Jama Psychiatry (2013) 70(8):793-802. doi:10.1001/ jamapsychiatry.2013.1270

22. Addington J, Cornblatt BA, Cadenhead KS, Cannon TD, McGlashan TH, Perkins DO, et al. At clinical high risk for psychosis: outcome for nonconverters. Am J Psychiatry (2011) 168(8):800-5. doi:10.1176/appi. ajp.2011.10081191

23. Putnam FW. The impact of trauma on child development. Juv Fam Court J (2006) 57(1):1-11. doi:10.1111/j.1755-6988.2006.tb00110.x

24. Tunnard C, Rane LJ, Wooderson SC, Markopoulou K, Poon L, Fekadu A, et al. The impact of childhood adversity on suicidality and clinical course in treatment-resistant depression. J Affect Disord (2014) 15(2-154):122-30. doi:10.1016/j.jad.2013.06.037

25. Ashford CD, Ashcroft K, Maguire N. Emotions, traits and negative beliefs as possible mediators in the relationship between childhood experiences of being bullied and paranoid thinking in a non-clinical sample. JExp Psychopathol (2012) 3(4):624-38. doi:10.5127/jep.020611

26. Bentall RP, Wickham S, Shevlin M, Varese F. Do specific early-life adversities lead to specific symptoms of psychosis? A study from the 2007 the adult psychiatric morbidity survey. Schizophr Bull (2012) 38(4):734-40. doi:10.1093/ schbul/sbs049

27. De Loore E, Drukker M, Gunther N, Feron F, Deboutte D, Sabbe B, et al. Childhood negative experiences and subclinical psychosis in adolescence: a longitudinal general population study. Early Interv Psychiatry (2007) 1(2):201-7. doi:10.1111/j.1751-7893.2007.00027.x

28. Heiervang E, Goodman R. Advantages and limitations of web-based surveys: evidence from a child mental health survey. Soc Psychiatry Psychiatr Epidemiol (2011) 46(1):69-76. doi:10.1007/s00127-009-0171-9

29. Kelleher I, Harley M, Lynch F, Arseneault L, Fitzpatrick C, Cannon M. Associations between childhood trauma, bullying and psychotic symptoms among a school-based adolescent sample. Br J Psychiatry (2008) 193(5):37882. doi:10.1192/bjp.bp.108.049536

30. Kelleher I, Keeley H, Corcoran P, Ramsay H, Wasserman C, Carli V, et al. Childhood trauma and psychosis in a prospective cohort study: cause, effect, and directionality. Am J Psychiatry (2013) 170(7):734-41. doi:10.1176/appi. ajp.2012.12091169

31. Lataster T, van Os J, Drukker M, Henquet C, Feron F, Gunther N, et al. Childhood victimisation and developmental expression of non-clinical delusional ideation and hallucinatory experiences: victimisation and non-clinical psychotic experiences. Soc Psychiatry Psychiatr Epidemiol (2006) 41(6):423-8. doi:10.1007/s00127-006-0060-4 
32. Campbell ML, Morrison AP. The relationship between bullying, psychoticlike experiences and appraisals in 14-16-year olds. Behav Res Ther (2007) 45(7):1579-91. doi:10.1016/j.brat.2006.11.009

33. Read J, van Os J, Morrison AP, Ross CA. Childhood trauma, psychosis and schizophrenia:aliterature reviewwith theoreticalandclinicalimplications. Acta Psychiatr Scand (2005) 112(5):330-50. doi:10.1111/j.1600-0447.2005.00634.x

34. Kraan T, van Dam DS, Velthorst E, de Ruigh EL, Nieman DH, Durston S, et al. Childhood trauma and clinical outcome in patients at ultra-high risk of transition to psychosis. Schizophr Res (2015) 169(1-3):193-8. doi:10.1016/j. schres.2015.10.030

35. Kessler RC, Sonnega A, Bromet E, Hughes M, Nelson CB. Posttraumatic stress disorder in the National Comorbidity Survey. Arch Gen Psychiatry (1995) 52(12):1048-60. doi:10.1001/archpsyc.1995.03950240066012

36. Finkelhor D, Ormrod R, Turner H, Hamby SL. The victimization of children and youth: a comprehensive, national survey. Child Maltreat (2005) 10(1):5-25. doi:10.1177/1077559504271287

37. Copeland WE, Keeler G, Angold A, Costello EJ. Traumatic events and posttraumatic stress in childhood. Arch Gen Psychiatry (2007) 64(5):577-84. doi:10.1001/archpsyc.64.5.577

38. Felitti VJ, Anda RF, Nordenberg D, Williamson DF, Spitz AM, Edwards V, et al. Relationship of childhood abuse and household dysfunction to many of the leading causes of death in adults. The Adverse Childhood Experiences (ACE) Study. Am J Prev Med (1998) 14(4):245-58.

39. Muenzenmaier KH, Seixas AA, Schneeberger AR, Castille DM, Battaglia J, Link BG. Cumulative effects of stressful childhood experiences on delusions and hallucinations. J Trauma Dissociation (2015) 16(4):442-62. doi:10.1080/15299732.2015.1018475

40. Bechdolf A, Thompson A, Nelson B, Cotton S, Simmons MB, Amminger GP, et al. Experience of trauma and conversion to psychosis in an ultrahigh-risk (prodromal) group. Acta Psychiatr Scand (2010) 121(5):377-84. doi:10.1111/j.1600-0447.2010.01542.x

41. Arseneault L, Cannon M, Fisher HL, Polanczyk G, Moffitt TE, Caspi A. Childhood trauma and children's emerging psychotic symptoms: a genetically sensitive longitudinal cohort study. Am J Psychiatry (2011) 168(1):65-72. doi:10.1176/appiajp.2010.10040567

42. Addington J, Stowkowy J, Cadenhead KS, Cornblatt BA, McGlashan TH, Perkins DO, et al. Early traumatic experiences in those at clinical high risk for psychosis. Early Interv Psychiatry (2013) 7(3):300-5. doi:10.1111/eip.12020

43. Devylder JE, Ben-David S, Schobel SA, Kimhy D, Malaspina D, Corcoran $\mathrm{CM}$. Temporal association of stress sensitivity and symptoms in individuals at clinical high risk for psychosis. Psychol Med (2013) 43(2):259-68. doi:10.1017/S0033291712001262

44. Falukozi E, Addington J. Impact of trauma on attenuated psychotic symptoms. Psychosis (2012) 4(3):203-12. doi:10.1080/17522439.2011.62686712

45. Kline E, Millman ZB, Denenny D, Wilson C, Thompson E, Demro C, et al. Trauma and psychosis symptoms in a sample of help-seeking youth. Schizophr Res (2016) 175(1-3):174-9. doi:10.1016/j.schres.2016.04.006

46. Magaud E, Nyman K, Addington J. Cyberbullying in those at clinical high risk for psychosis. Early Interv Psychiatry (2013) 7(4):427-30. doi:10.1111/ eip. 12013

47. Mason O, Startup M, Halpin S, Schall U, Conrad A, Carr V. Risk factors for transition to first episode psychosis among individuals with 'at-risk mental states'. Schizophr Res (2004) 71(2-3):227-37. doi:10.1016/j.schres.2004.04.006

48. Phillips LJ, Edwards J, McMurray N, Francey S. Comparison of experiences of stress and coping between young people at risk of psychosis and a non-clinical cohort. Behav Cogn Psychother (2012) 40(1):69-88. doi:10.1017/ S1352465811000397

49. Russo DA, Stochl J, Painter M, Dobler V, Jackson E, Jones PB, et al. Trauma history characteristics associated with mental states at clinical high risk for psychosis. Psychiatry Res (2014) 220(1-2):237-44. doi:10.1016/j.psychres. 2014.08.028

50. Stowkowy J, Addington J. Predictors of a clinical high risk status among individuals with a family history of psychosis. Schizophr Res (2013) 147(2-3):281-6. doi:10.1016/j.schres.2013.03.030

51. Stowkowy J, Liu L, Cadenhead KS, Cannon TD, Cornblatt BA, McGlashan $\mathrm{TH}$, et al. Early traumatic experiences, perceived discrimination and conversion to psychosis in those at clinical high risk for psychosis. Soc Psychiatry Psychiatr Epidemiol (2016) 51(4):497-503. doi:10.1007/s00127-016-1182-y
52. Thompson A, Marwaha S, Nelson B, Wood SJ, McGorry PD, Yung AR, et al. Do affective or dissociative symptoms mediate the association between childhood sexual trauma and transition to psychosis in an ultra-high risk cohort? Psychiatry Res (2016) 236:182-5. doi:10.1016/j.psychres.2016.01.017

53. Thompson A, Nelson B, McNab C, Simmons M, Leicester S, McGorry PD, et al. Psychotic symptoms with sexual content in the "ultra high risk" for psychosis population: frequency and association with sexual trauma. Psychiatry Res (2010) 177(1-2):84-91. doi:10.1016/j.psychres.2010.02.011

54. Thompson A, Papas A, Bartholomeusz C, Nelson B, Yung A. Externalized attributional bias in the ultra high risk (UHR) for psychosis population. Psychiatry Res (2013) 206(2-3):200-5. doi:10.1016/j.psychres.2012.10.017

55. Thompson AD, Nelson B, Yuen HP, Lin A, Amminger GP, McGorry PD, et al. Sexual trauma increases the risk of developing psychosis in an ultra high-risk "prodromal" population. Schizophr Bull (2014) 40(3):697-706. doi:10.1093/ schbul/sbt032

56. Thompson JL, Kelly M, Kimhy D, Harkavy-Friedman JM, Khan S, Messinger JW, et al. Childhood trauma and prodromal symptoms among individuals at clinical high risk for psychosis. Schizophr Res (2009) 108(1-3):176-81. doi:10.1016/j.schres.2008.12.005

57. Thompson KN, Phillips LJ, Komesaroff P, Yuen HP, Wood SJ, Pantelis C, et al. Stress and HPA-axis functioning in young people at ultra high risk for psychosis. J Psychiatr Res (2007) 41(7):561-9. doi:10.1016/j.jpsychires.2006. 05.010

58. Tikka M, Luutonen S, Ilonen T, Tuominen L, Kotimaki M, Hankala J, et al. Childhood trauma and premorbid adjustment among individuals at clinical high risk for psychosis and normal control subjects. Early Interv Psychiatry (2013) 7(1):51-7. doi:10.1111/j.1751-7893.2012.00391.x

59. Üçok A, Kaya H, Ugurpala C, Cikrikcili U, Ergul C, Yokusoglu C, et al. History of childhood physical trauma is related to cognitive decline in individuals with ultra-high risk for psychosis. Schizophr Res (2015) 169(1-3):199-203. doi:10.1016/j.schres.2015.08.038

60. Velthorst E, Nelson B, O'Connor K, Mossaheb N, de Haan L, Bruxner A, et al. History of trauma and the association with baseline symptoms in an ultra-high risk for psychosis cohort. Psychiatry Res (2013) 210(1):75-81. doi:10.1016/j.psychres.2013.06.007

61. Yung AR, Cotter J, Wood SJ, McGorry P, Thompson AD, Nelson B, et al. Childhood maltreatment and transition to psychotic disorder independently predict long-term functioning in young people at ultra-high risk for psychosis. Psychol Med (2015) 45(16):3453-65. doi:10.1017/ S003329171500135X

62. Zimbron J, Ruiz de Azua S, Khandaker GM, Gandamaneni PK, Crane CM, Gonzalez-Pinto A, et al. Clinical and sociodemographic comparison of people at high-risk for psychosis and with first-episode psychosis. Acta Psychiatr Scand (2013) 127(3):210-6. doi:10.1111/acps.12000

63. Asendorpf JB, Conner M, De Fruyt F, De Houwer J, Denissen JJ, Fiedler K, et al. Recommendations for increasing replicability in psychology. Eur J Pers (2013) 27(2):108-19. doi:10.1002/per.1919

64. U.S. Department of Health and Human Services, Administration for Children and Families, Administration on Children Youth and Families, Children's Bureau. Child Maltreatment 2014. (2016). Available from http://www.acf. hhs.gov/programs/cb/research-data-technology/statistics-research/childmaltreatment

65. Dube SR, Anda RF, Whitfield CL, Brown DW, Felitti VJ, Dong M, et al. Longterm consequences of childhood sexual abuse by gender of victim. Am J Prev Med (2005) 28(5):430-8. doi:10.1016/j.amepre.2005.01.015

66. Al Mamun A, Alati R, O’Callaghan M, Hayatbakhsh MR, O'Callaghan FV, Najman JM, et al. Does childhood sexual abuse have an effect on young adults' nicotine disorder (dependence or withdrawal)? Evidence from a birth cohort study. Addiction (2007) 102(4):647-54. doi:10.1111/j.1360-0443.2006.01732.x/abstract

67. Kendler KS, Bulik CM, Silberg J, Hettema JM, Myers J, Prescott CA. Childhood sexual abuse and adult psychiatric and substance use disorders in women: an epidemiological and Cotwin control analysis. Arch Gen Psychiatry (2000) 57(10):953-9. doi:10.1001/archpsyc.57.10.953

68. Young MS, Harford K-L, Kinder B, Savell JK. The relationship between childhood sexual abuse and adult mental health among undergraduates: victim gender doesn't matter. J Interpers Violence (2007) 22(10):1315-31. doi:10.1177/0886260507304552 
69. Leserman J. Sexual abuse history: prevalence, health effects, mediators, and psychological treatment. Psychosom Med (2005) 67(6):906-15. doi:10.1097/01.psy.0000188405.54425.20

70. Child Welfare Information Gateway. Definitions of Child Abuse and Neglect. Washington, DC: U.S. Department of Health and Human Services Children's Bureau (2016).

71. Arseneault L, Bowes L, Shakoor S. Bullying victimization in youths and mental health problems: 'much ado about nothing'? Psychol Med (2010) 40(5):717-29. doi:10.1017/S0033291709991383

72. Frame L, Morrison AP. Causes of posttraumatic stress disorder in psychotic patients. Arch Gen Psychiatry (2001) 58(3):305-6. doi:10.1001/ archpsyc.58.3.305

73. Meyer H, Taiminen T, Vuori T, Aijala A, Helenius H. Posttraumatic stress disorder symptoms related to psychosis and acute involuntary hospitalization in schizophrenic and delusional patients. J Nerv Ment Dis (1999) 187(6):343-52. doi:10.1097/00005053-199906000-00003

74. Reddy LF, Spaulding WD. Understanding adverse experiences in the psychiatric institution: the importance of child abuse histories in iatrogenic trauma. Psychol Serv (2010) 7(4):242-53. doi:10.1037/a0020316

75. Berry K, Ford S, Jellicoe-Jones L, Haddock G. PTSD symptoms associated with the experiences of psychosis and hospitalisation: a review of the literature. Clin Psychol Rev (2013) 33(4):526-38. doi:10.1016/j.cpr.2013.01.011

76. Centofanti AT, Smith DI, Altieri T. Posttraumatic stress disorder as a reaction to the experience of psychosis and its sequelae. Clin Psychol (2005) 9(1):15-23. doi:10.1080/13284200500116963

77. Gibson LE, Anglin DM, Klugman JT, Reeves LE, Fineberg AM, Maxwell $\mathrm{SD}$, et al. Stress sensitivity mediates the relationship between traumatic life events and attenuated positive psychotic symptoms differentially by gender in a college population sample. J Psychiatr Res (2014) 53:111-8. doi:10.1016/j. jpsychires.2014.02.020

78. Garcia M, Montalvo I, Creus M, Cabezas A, Sole M, Algora MJ, et al. Sex differences in the effect of childhood trauma on the clinical expression of early psychosis. Compr Psychiatry (2016) 68:86-96. doi:10.1016/j. comppsych.2016.04.004

79. Chapman DP, Whitfield CL, Felitti VJ, Dube SR, Edwards VJ, Anda RF. Adverse childhood experiences and the risk of depressive disorders in adulthood. J Affect Disord (2004) 82(2):217-25. doi:10.1016/j.jad.2003.12.013

80. Whitfield CL, Dube SR, Felitti VJ, Anda RF. Adverse childhood experiences and hallucinations. Child Abuse Negl (2005) 29(7):797-810. doi:10.1016/j. chiabu.2005.01.004

81. Wolke D, Lereya ST, Fisher HL, Lewis G, Zammit S. Bullying in elementary school and psychotic experiences at 18 years: a longitudinal, population-based cohort study. Psychol Med (2014) 44(10):2199-211. doi:10.1017/ S0033291713002912

82. Trotta A, Di Forti M, Mondelli V, Dazzan P, Pariante C, David A, et al. Prevalence of bullying victimisation amongst first-episode psychosis patients and unaffected controls. Schizophr Res (2013) 150(1):169-75. doi:10.1016/j. schres.2013.07.001

83. Shakoor S, McGuire P, Cardno AG, Freeman D, Plomin R, Ronald A. A shared genetic propensity underlies experiences of bullying victimization in late childhood and self-rated paranoid thinking in adolescence. Schizophr Bull (2015) 41(3):754-63. doi:10.1093/schbul/sbu142

84. Schreier A, Wolke D, Thomas K, Horwood J, Hollis C, Gunnell D, et al. Prospective study of peer victimization in childhood and psychotic symptoms in a nonclinical population at age 12 years. Arch Gen Psychiatry (2009) 66(5):527-36. doi:10.1001/archgenpsychiatry.2009.23

85. Bond L, Carlin JB, Thomas L, Rubin K, Patton G. Does bullying cause emotional problems? A prospective study of young teenagers. BMJ (2001) 323(7311):480-4. doi:10.1136/bmj.323.7311.480

86. Walker E. Independent and joint predictive power of life events, daily stress, and cortisol in relation to conversion to psychosis. Psychoneuroendocrinology (2016) 71:9. doi:10.1016/j.psyneuen.2016.07.032

87. Beards S, Gayer-Anderson C, Borges S, Dewey ME, Fisher HL, Morgan C. Life events and psychosis: a review and meta-analysis. Schizophr Bull (2013) 39(4):740-7. doi:10.1093/schbul/sbt065

88. Niendam TA, Berzak J, Cannon TD, Bearden CE. Obsessive compulsive symptoms in the psychosis prodrome: correlates of clinical and functional outcome. Schizophr Res (2009) 108(1-3):170-5. doi:10.1016/j. schres.2008.11.023
89. Fusar-Poli P, Nelson B, Valmaggia L, Yung AR, McGuire PK. Comorbid depressive and anxiety disorders in 509 individuals with an at-risk mental state: impact on psychopathology and transition to psychosis. Schizophr Bull (2014) 40(1):120-31. doi:10.1093/schbul/sbs136

90. Salokangas RK, Ruhrmann S, von Reventlow HG, Heinimaa M, Svirskis T, From T, et al. Axis I diagnoses and transition to psychosis in clinical high-risk patients EPOS project: prospective follow-up of 245 clinical high-risk outpatients in four countries. Schizophr Res (2012) 138(2-3):192-7. doi:10.1016/j. schres.2012.03.008

91. Rutigliano G, Valmaggia L, Landi P, Frascarelli M, Cappucciati M, Sear V, et al. Persistence or recurrence of non-psychotic comorbid mental disorders associated with 6-year poor functional outcomes in patients at ultra high risk for psychosis. J Affect Disord (2016) 203:101-10. doi:10.1016/j. jad.2016.05.053

92. Lin A, Wood SJ, Nelson B, Beavan A, McGorry P, Yung AR. Outcomes of nontransitioned cases in a sample at ultra-high risk for psychosis. Am J Psychiatry (2015) 172(3):249-58. doi:10.1176/appi.ajp.2014.13030418

93. Fairbank JA, Putnam FW, Harris WW. The prevalence and impact of child traumatic stress. In: Friedman MJ, Keane TM, Resick PA, editors. Handbook of PTSD: Science and Practice. New York, NY: The Guilford Press (2007). p. 229-51.

94. Spence W, Mulholland C, Lynch G, McHugh S, Dempster M, Shannon C. Rates of childhood trauma in a sample of patients with schizophrenia as compared with a sample of patients with non-psychotic psychiatric diagnoses. J Trauma Dissociation (2006) 7(3):7-22. doi:10.1300/J229v07n03_02

95. Lysaker PH, Davis LW, Gatton MJ, Herman SM. Associations of anxietyrelated symptoms with reported history of childhood sexual abuse in schizophrenia spectrum disorders. J Clin Psychiatry (2005) 66(10):1279-84. doi:10.4088/JCP.v66n1010

96. Addington J, Case N, Saleem MM, Auther AM, Cornblatt BA, Cadenhead KS. Substance use in clinical high risk for psychosis: a review of the literature. Early Interv Psychiatry (2014) 8(2):104-12. doi:10.1111/eip.12100

97. Simpson TL, Miller WR. Concomitance between childhood sexual and physical abuse and substance use problems: a review. Clin Psychol Rev (2002) 22(1):27-77. doi:10.1016/S0272-7358(00)00088-X

98. Buchy L, Cadenhead KS, Cannon TD, Cornblatt BA, McGlashan TH, Perkins DO, et al. Substance use in individuals at clinical high risk of psychosis. Psychol Med (2015) 45(11):2275-84. doi:10.1017/S0033291715000227

99. Paparelli A, Di Forti M, Morrison PD, Murray RM. Drug-induced psychosis: how to avoid star gazing in schizophrenia research by looking at more obvious sources of light. Front Behav Neurosci (2011) 5:1. doi:10.3389/ fnbeh.2011.00001

100. Harley M, Kelleher I, Clarke M, Lynch F, Arseneault L, Connor D, et al. Cannabis use and childhood trauma interact additively to increase the risk of psychotic symptoms in adolescence. Psychol Med (2010) 40(10):1627-34. doi:10.1017/S0033291709991966

101. Addington J, Cadenhead KS, Cornblatt BA, Mathalon DH, McGlashan TH, Perkins DO, et al. North American prodrome longitudinal study (NAPLS 2): overview and recruitment. Schizophr Res (2012) 142(1):77-82. doi:10.1016/j. schres.2012.09.012

102. Morrison AP, Frame L, Larkin W. Relationships between trauma and psychosis: a review and integration. Br J Clin Psychol (2003) 42(4):331-53. doi:10.1348/014466503322528892

103. Graham Scott J, Nurcombe B, Sheridan J, McFarland M. Hallucinations in adolescents with post-traumatic stress disorder and psychotic disorder. Australas Psychiatry (2007) 15(1):44-8. doi:10.1080/10398560601083084

104. Jessop M, Scott J, Nurcombe B. Hallucinations in adolescent inpatients with post-traumatic stress disorder and schizophrenia: similarities and differences. Australas Psychiatry (2008) 16(4):268-72. doi:10.1080/10398560801982580

105. Sareen J, Cox BJ, Goodwin RD, JG Asmundson G. Co-occurrence of posttraumatic stress disorder with positive psychotic symptoms in a nationally representative sample. J Trauma Stress (2005) 18(4):313-22. doi:10.1002/ jts. 20040

106. Alsawy S, Wood L, Taylor P, Morrison A. Psychotic experiences and PTSD: exploring associations in a population survey. Psychol Med (2015) 45(13):2849-59. doi:10.1017/S003329171500080X

107. Shevlin M, Dorahy M, Adamson G. Childhood traumas and hallucinations: an analysis of the national comorbidity survey. J Psychiatr Res (2007) 41(3):222-8. doi:10.1016/j.jpsychires.2006.03.004 
108. Famularo R, Fenton T, Kinscherff R, Augustyn M. Psychiatric comorbidity in childhood post traumatic stress disorder. Child Abuse Negl (1996) 20(10):953-61. doi:10.1016/0145-2134(96)00084-1

109. Husted JA, Ahmed R, Chow EW, Brzustowicz LM, Bassett AS. Childhood trauma and genetic factors in familial schizophrenia associated with the NOS1AP gene. Schizophr Res (2010) 121(1):187-92. doi:10.1016/j. schres.2010.05.021

110. Bernardo M, Bioque M, Cabrera B, Lobo A, Gonzalez-Pinto A, Pina L, et al. Modelling gene-environment interaction in first episodes of psychosis. Schizophr Res (2017). doi:10.1016/j.schres.2017.01.058

111. Zubin J, Spring B. Vulnerability: a new view of schizophrenia. J Abnorm Psychol (1977) 86(2):103-26. doi:10.1037/0021-843X.86.2.103

112. Harkness KL, Hayden EP, Lopez-Duran NL. Stress sensitivity and stress sensitization in psychopathology: an introduction to the special section. J Abnorm Psychol (2015) 124(1):1-3. doi:10.1037/abn0000041

113. Monroe SM, Harkness KL. Life stress, the "Kindling" hypothesis, and the recurrence of depression: considerations from a life stress perspective. Psychol Rev (2005) 112(2):417-45. doi:10.1037/0033-295x.112.2.417

114. Walker E, Diforio D. Schizophrenia: a neural diathesis-stress model. Psychol $\operatorname{Rev}(1997)$ 104(4):667-85. doi:10.1037/0033-295X.104.4.667

115. Meyers JL, Lowe SR, Eaton NR, Krueger R, Grant BF, Hasin D. Childhood maltreatment, 9/11 exposure, and latent dimensions of psychopathology: a test of stress sensitization. J Psychiatr Res (2015) 68:337-45. doi:10.1016/j. jpsychires.2015.05.005

116. Trotman HD, Holtzman CW, Walker EF, Addington JM, Bearden CE, Cadenhead KS, et al. Stress exposure and sensitivity in the clinical high-risk syndrome: initial findings from the North American Prodrome Longitudinal Study (NAPLS). Schizophr Res (2014) 160(1-3):104-9. doi:10.1016/j. schres.2014.09.017

117. Kahn JP, Rubinow DR, Davis CL, Kling M, Post RM. Salivary cortisol: a practical method for evaluation of adrenal function. Biol Psychiatry (1988) 23(4):335-49. doi:10.1016/0006-3223(88)90284-3

118. Day FL, Valmaggia LR, Mondelli V, Papadopoulos A, Papadopoulos I, Pariante CM, et al. Blunted cortisol awakening response in people at ultra high risk of developing psychosis. Schizophr Res (2014) 158(1-3):25-31. doi:10.1016/j.schres.2014.06.041

119. Pruessner M, Bechard-Evans L, Boekestyn L, Iyer SN, Pruessner JC, Malla AK. Attenuated cortisol response to acute psychosocial stress in individuals at ultra-high risk for psychosis. Schizophr Res (2013) 146(1-3):79-86. doi:10.1016/j.schres.2013.02.019

120. Walker E, Mittal V, Tessner K. Stress and the hypothalamic pituitary adrenal axis in the developmental course of schizophrenia. Annu Rev Clin Psychol (2008) 4:189-216. doi:10.1146/annurev.clinpsy.4.022007.141248

121. Girshkin L, Matheson SL, Shepherd AM, Green MJ. Morning cortisol levels in schizophreniaandbipolardisorder:ameta-analysis. Psychoneuroendocrinology (2014) 49:187-206. doi:10.1016/j.psyneuen.2014.07.013

122. Bradley AJ, Dinan TG. A systematic review of hypothalamic-pituitary-adrenal axis function in schizophrenia: implications for mortality. J Psychopharmacol (2010) 24(4 Suppl):91-118. doi:10.1177/1359786810385491

123. Sugranyes G, Thompson JL, Corcoran CM. HPA-axis function, symptoms, and medication exposure in youths at clinical high risk for psychosis. J Psychiatr Res (2012) 46(11):1389-93. doi:10.1016/j.jpsychires.2012.07.011

124. Van Voorhees E, Scarpa A. The effects of child maltreatment on the hypothalamic-pituitary-adrenal axis. Trauma Violence Abuse (2004) 5(4):333-52. doi:10.1177/1524838004269486

125. Martinson A, Craner J, Sigmon S. Differences in HPA axis reactivity to intimacy in women with and without histories of sexual trauma. Psychoneuroendocrinology (2016) 65:118-26. doi:10.1016/j.psyneuen. 2015.12.025

126. Braehler C, Holowka D, Brunet A, Beaulieu S, Baptista T, Debruille JB, et al. Diurnal cortisol in schizophrenia patients with childhood trauma. Schizophr Res (2005) 79(2):353-4. doi:10.1016/j.schres.2004.07.007

127. Phassouliotis C, Garner BA, Phillips LJ, Bendall S, Yun Y, Markulev C, et al. Enhanced cortisol suppression following administration of low-dose dexamethasone in first-episode psychosis patients. Aust N Z J Psychiatry (2013) 47(4):363-70. doi:10.1177/0004867412465125

128. Pruessner JC, Champagne F, Meaney MJ, Dagher A. Dopamine release in response to a psychological stress in humans and its relationship to early life maternal care: a positron emission tomography study using [11C]raclopride. J Neurosci (2004) 24(11):2825-31. doi:10.1523/JNEUROSCI.3422-03.2004

129. Bois C, Whalley H, McIntosh A, Lawrie S. Structural magnetic resonance imaging markers of susceptibility and transition to schizophrenia: a review of familial and clinical high risk population studies. J Psychopharmacol (2015) 29(2):144-54. doi:10.1177/0269881114541015

130. Howes OD, McCutcheon R, Owen MJ, Murray RM. The role of genes, stress, and dopamine in the development of schizophrenia. Biol Psychiatry (2017) 81(1):9-20. doi:10.1016/j.biopsych.2016.07.014

131. Howes OD, Bose SK, Turkheimer F, Valli I, Egerton A, Valmaggia LR, et al. Dopamine synthesis capacity before onset of psychosis: a prospective [18F]-DOPA PET imaging study. Am J Psychiatry (2011) 168(12):1311-7. doi:10.1176/appi.ajp.2011.11010160

132. Oswald LM, Wand GS, Kuwabara H, Wong DF, Zhu S, Brasic JR. History of childhood adversity is positively associated with ventral striatal dopamine responses to amphetamine. Psychopharmacology (2014) 231(12):2417-33. doi:10.1007/s00213-013-3407-z

133. Chaumette B, Kebir O, Mam-Lam-Fook C, Morvan Y, Bourgin J, Godsil BP, et al. Salivary cortisol in early psychosis: new findings and meta-analysis. Psychoneuroendocrinology (2016) 63:262-70. doi:10.1016/j. psyneuen.2015.10.007

134. Walker EF, Trotman HD, Pearce BD, Addington J, Cadenhead KS, Cornblatt BA, et al. Cortisol levels and risk for psychosis: initial findings from the North American prodrome longitudinal study. Biol Psychiatry (2013) 74(6):410-7. doi:10.1016/j.biopsych.2013.02.016

135. Addington J, Tran L. Using the brief core schema scales with individuals at clinical high risk of psychosis. Behav Cogn Psychother (2009) 37(2):227-31. doi:10.1017/S1352465809005116

136. van Os J, Krabbendam L, Myin-Germeys I, Delespaul P. The schizophrenia envirome. Curr Opin Psychiatry (2005) 18(2):141-5. doi:10.1097/ 00001504-200503000-00006

137. Nieman DH, Ruhrmann S, Dragt S, Soen F, van Tricht MJ, Koelman JH, et al. Psychosis prediction: stratification of risk estimation with informationprocessing and premorbid functioning variables. Schizophr Bull (2014) 40(6):1482-90. doi:10.1093/schbul/sbt145

138. Roiser JP, Howes OD, Chaddock CA, Joyce EM, McGuire P. Neural and behavioral correlates of aberrant salience in individuals at risk for psychosis. Schizophr Bull (2013) 39(6):1328-36. doi:10.1093/schbul/sbs147

139. van Os J, Reininghaus U. Psychosis as a transdiagnostic and extended phenotype in the general population. World Psychiatry (2016) 15(2):118-24. doi:10.1002/wps.20310

140. Sherrer MV. The role of cognitive appraisal in adaptation to traumatic stress in adults with serious mental illness: a critical review. Trauma Violence Abuse (2011) 12(3):151-67. doi:10.1177/1524838011404254

141. Gibson LE, Alloy LB, Ellman LM. Trauma and the psychosis spectrum: a review of symptom specificity and explanatory mechanisms. Clin Psychol Rev (2016) 49:92-105. doi:10.1016/j.cpr.2016.08.003

142. Evans GJ, Reid G, Preston P, Palmier-Claus J, Sellwood W. Trauma and psychosis: the mediating role of self-concept clarity and dissociation. Psychiatry Res (2015) 228(3):626-32. doi:10.1016/j.psychres.2015.04.053

143. Palmier-Claus J, Berry K, Darrell-Berry H, Emsley R, Parker S, Drake R, et al. Childhood adversity and social functioning in psychosis: exploring clinical and cognitive mediators. Psychiatry Res (2016) 238:25-32. doi:10.1016/j. psychres.2016.02.004

144. Coryell W, Leon A, Winokur G, Endicott J, Keller M, Akiskal H, et al. Importance of psychotic features to long-term course in major depressive disorder. Am J Psychiatry (1996) 153(4):483. doi:10.1176/ajp.153.4.483

145. Keck PE Jr, McElroy SL, Havens JR, Altshuler LL, Nolen WA, Frye MA, et al. Psychosis in bipolar disorder: phenomenology and impact on morbidity and course of illness. Compr Psychiatry (2003) 44(4):263-9. doi:10.1016/ S0010-440X(03)00089-0

146. The National Child Traumatic Stress Network. Trauma-Informed Screening \& Assessment. (n.d.) (2015). Available from: http://www.nctsn.org/resources/ topics/trauma-informed-screening-assessment/trauma-screening

147. Cohen JA, Bukstein O, Walter H, Benson SR, Chrisman A, Farchione TR, et al. Practice parameter for the assessment and treatment of children and adolescents with posttraumatic stress disorder. J Am Acad Child Adolesc Psychiatry (2010) 49(4):414-30. doi:10.1016/j.jaac.2009.12.020 
148. Schnurr P, Vielhauer M, Weathers F, Findler M. The Brief Trauma Questionnaire. White River Junction, VT: National Center for PTSD (1999).

149. Bernstein DP, Stein JA, Newcomb MD, Walker E, Pogge D, Ahluvalia T, et al. Development and validation of a brief screening version of the childhood trauma questionnaire. Child Abuse Negl (2003) 27(2):169-90. doi:10.1016/ S0145-2134(02)00541-0

150. Briere J. Trauma Symptom Checklist for Children (TSCC): Professional Manual. Odessa, FL: Psychological Assessment Resources (1996).

151. Foa EB, Johnson KM, Feeny NC, Treadwell KRH. The child PTSD symptom scale: a preliminary examination of its psychometric properties. J Clin Child Psychol (2001) 30(3):376-84. doi:10.1207/S15374424JCCP3003_9

152. Rodriguez N, Steinberg A, Pynoos R. UCLA Posttraumatic Stress Disorder Reaction Index for DSM-IV: Child, Adolescent, and Parent versions. Los Angeles, CA: University of California at Los Angeles (1998).

153. Briere J. Trauma Symptom Checklist for Young Children. Odessa, FL: Psychological Assessment Resources, Inc (2005).

154. First M, Spitzer RL, Gibbon M, Williams B, Williams JBW. Structured Clinical Interview for DSM-IV Axis I Disorders, Patient Edition. New York: Biometrics Research Department, New York State Psychiatric Institute (1995).

155. Puig-Antich J, Ryan N. Kiddie Schedule for Affective Disorders and Schizophrenia. Pittsburgh, PA: Western Psychiatric Institute (1986).

156. Fisher HL, Craig TK, Fearon P, Morgan K, Dazzan P, Lappin J, et al. Reliability and comparability of psychosis patients' retrospective reports of childhood abuse. Schizophr Bull (2011) 37(3):546-53. doi:10.1093/schbul/sbp103

157. Kassam-Adams N, Newman E. Child and parent reactions to participation in clinical research. Gen Hosp Psychiatry (2005) 27(1):29-35. doi:10.1016/j. genhosppsych.2004.08.007
158. Legerski JP, Bunnell SL. The risks, benefits, and ethics of trauma-focused research participation. Ethics Behav (2010) 20(6):429-42. doi:10.1080/ 10508422.2010.521443

159. Cragin CA, Straus MB, Blacker D, Tully LM, Niendam TA. Early psychosis and trauma-related disorders: clinical practice guidelines and future directions. Front Psychiatry (2017) 8:33. doi:10.3389/fpsyt.2017.00033

160. de Bont $\mathrm{P}$, van den Berg D, van der Vleugel B, de Roos C, de Jongh A, van der Gaag M, et al. Prolonged exposure and EMDR for PTSD v. a PTSD waiting-list condition: effects on symptoms of psychosis, depression and social functioning in patients with chronic psychotic disorders. Psychol Med (2016) 46(11):2411. doi:10.1017/S0033291716001094

161. van den Berg DP, van der Vleugel BM, de Bont PA, Thijssen G, de Roos C, de Kleine R, et al. Exposing therapists to trauma-focused treatment in psychosis: effects on credibility, expected burden, and harm expectancies. Eur J Psychotraumatol (2016) 7:31712. doi:10.3402/ejpt.v7.31712

Conflict of Interest Statement: The authors declare that the research was conducted in the absence of any commercial or financial relationships that could be construed as a potential conflict of interest.

Copyright (C) 2017 Mayo, Corey, Kelly, Yohannes, Youngquist, Stuart, Niendam and Loewy. This is an open-access article distributed under the terms of the Creative Commons Attribution License (CC BY). The use, distribution or reproduction in other forums is permitted, provided the original author(s) or licensor are credited and that the original publication in this journal is cited, in accordance with accepted academic practice. No use, distribution or reproduction is permitted which does not comply with these terms. 